\title{
Optical, UV-Vis spectroscopy studies, electrical and dielectric properties of transition metal-based of the novel organic-inorganic hybrid $\left(\mathrm{C}_{6} \mathrm{H}_{10} \mathrm{~N}_{2}\right)\left(\mathrm{Hg}_{2} \mathrm{Cl}_{5}\right)_{2} \cdot 3 \mathrm{H}_{2} \mathrm{O}$
}

\author{
Imen Ben Saad*, Najeh Hannachi*, ${ }^{*}$, Thierry Roisnel ${ }^{\dagger}$ and Faouzi Hlel* \\ *Laboratory of Spectroscopic Characterization and Optics of Materials \\ Faculty of Sciences, University of Sfax \\ B. P. 1171, 3000 Sfax, Tunisia \\ ${ }^{\dagger}$ University of Rennes, CNRS, ISCR \\ (Institut des Sciences Chimiques de Rennes) - UMR 6226 \\ F-35000 Rennes, France \\ 市nejeh@yahoo.fr
}

Received 29 August 2019; Revised 6 October 2019; Accepted 9 October 2019; Published 21 November 2019

\begin{abstract}
In this work, we are interested in the synthesis of new hybrid material $\left(\mathrm{C}_{6} \mathrm{H}_{10} \mathrm{~N}_{2}\right)\left(\mathrm{Hg}_{2} \mathrm{Cl}_{5}\right)_{2} \cdot 3 \mathrm{H}_{2} \mathrm{O}$ grown by hydrothermal methods. $\mathrm{X}$-ray diffraction indicates that this compound crystallizes at $150(2) \mathrm{K}$ in the monoclinic system with $C 2 / c$ space group, with the following unit cell parameters: $a=19.6830(15) \AA, b=18.1870(15) \AA, c=6.8567(6) \AA, \beta=93.224(3)^{\circ}$ and $Z=4$. On the other hand, the optical properties of this compound were studied using ultraviolet-visible (UV-Vis) spectroscopy in the range 200$800 \mathrm{~nm}$. Furthermore, the optical absorbances are used to determine the absorption coefficient $\alpha$ and the optical band gap $E_{g}$, so the Tauc model was used to determine the optical gap energy of the compound $\left(\mathrm{C}_{6} \mathrm{H}_{10} \mathrm{~N}_{2}\right)\left(\mathrm{Hg}_{2} \mathrm{Cl}_{5}\right)_{2} \cdot 3 \mathrm{H}_{2} \mathrm{O}$. The analysis of the results revealed the existence of optical allowed indirect transition mechanisms with the band gap energy equal to (2.37 eV) for liquid and $(4.33 \mathrm{eV})$ for solid. Impedance measurements indicate that the electrical and dielectric properties are strongly dependent on both temperature and frequency. Nyquist plots $\left(Z^{\prime \prime}\right.$ versus $\left.Z^{\prime}\right)$ show that the conductivity behavior is accurately represented by an equivalent circuit model which consists of a series combination of bulk and grain boundary. Furthermore, the angular frequency dependence plots of the real and imaginary parts, $\varepsilon^{\prime}$ and $\varepsilon^{\prime \prime}$, of complex dielectric permittivity $\varepsilon *$ and $\tan \delta$ losses at several temperatures between 303 and $453 \mathrm{~K}$ were studied for the title compound. Finally, the modulus plots can be characterized by the presence of two relaxation peaks.
\end{abstract}

Keywords: Optical properties; UV-Vis spectroscopy; the impedance spectroscopy; the temperature (303-453 K) and frequency dependence of the electrical conductivity and the dielectric properties.

\section{Introduction}

Hybrid organic-inorganic materials are one of the fastestgrowing and most promising research areas in solid-state chemistry. Doing a combination of inorganic and organic structural components, they can be described as sequences of alternating organic-inorganic layers. For these materials, the ammonium ion of the organic group builds a hydrogen bond with the halide ion of the inorganic layer, which makes these hybrid compounds good candidates for proton conduction with high potential technological applications. ${ }^{1-4}$ For this purpose, Mercury (II) halides are considered as one of the immense and the importance fields in chemistry and related disciplines due to their potential applications in the paper industry, paints, cosmetics, fluorescent lamps, sensors and mercury batteries. ${ }^{5-12}$ Mercury exists in several different chemical forms obtained by three oxidation states $\left(\mathrm{Hg}^{0}\right.$, $\mathrm{Hg}_{2}^{2+}$ and $\mathrm{Hg}^{2+}$ ) which have a strong affinity for many inorganic $\left(\mathrm{HgL}_{i}\right)$ and organic ligands mercury $\left(\mathrm{HgX}_{i}\right){ }^{1,13,14}$ The structural chemistry of $\mathrm{Hg}$ (II) halides in the solid-state is exceptionally diverse. Indeed, the $\mathrm{Hg}$ (II) represents a potential class of materials with unusual structural archetypes. This is due to the fact that the $\mathrm{Hg}^{2+}$ being a $6 \mathrm{~s}^{2}$ and $5 \mathrm{~d}^{10}$ ion exhibits a variety of coordination numbers and geometries, depending on crystal packing and legends (octahedral and tetrahedral typically being observed) as well as halide dimensions. ${ }^{15-19}$ In addition, mercury (II) halides are compounds of current interest due to their possible applications as materials with nonlinear optical properties. ${ }^{20}$ On the other hand, the organic compounds with aromatic moieties, exhibit higher nonlinear optical properties, with a strong donor-acceptor intermolecular interaction. ${ }^{21-23}$ Moreover, they have special properties which are due to the presence of delocalized electron. This compound has great interest due to the remarkable physical properties. ${ }^{24-32}$ Significant effort has been placed on both experimental and theoretical studies in this family of compounds in order to understand dynamical behavior. Furthermore, particular attention is paid to compounds that have electrical, magnetic and thermodynamic

This is an Open Access article published by World Scientific Publishing Company. It is distributed under the terms of the Creative Commons Attribution 4.0 (CC BY) License which permits use, distribution and reproduction in any medium, provided the original work is properly cited. 
properties; the latter is useful in many applications. ${ }^{18}$ To give more information on crystal dynamics, impedance spectroscopy is a very useful technique in solid-state because it is one of the methods that is able to give valuable information about conduction mechanism and to understand the nature and the origin of dielectric losses. ${ }^{33,34}$

Inspired by these pioneering works, we wish to study the optical properties of $\left(\mathrm{C}_{6} \mathrm{H}_{10} \mathrm{~N}_{2}\right)\left(\mathrm{Hg}_{2} \mathrm{Cl}_{5}\right)_{2} \cdot 3 \mathrm{H}_{2} \mathrm{O}$. The structural arrangement of this compound can be described as cationic layer alternate with anionic layer stacked along $c$-direction. The crystal package is provided by hydrogen bonding $\left(\mathrm{N}-\mathrm{H}^{* * *} \mathrm{Cl}\right),\left(\mathrm{N}-\mathrm{H}^{* * *} \mathrm{O}\right),\left(\mathrm{O}-\mathrm{H}^{* * *} \mathrm{O}\right)$ and $\pi-\pi$ interactions. The anionic layer is formed by an assembly of two in-equivalent triangles determined by the association of two monomercury chloride $\mathrm{HgCl}_{3}^{-}$units which carry a chlorine atom-common $\mathrm{Cl}_{(3)}$. The organic network is formed by $\left(\mathrm{C}_{6} \mathrm{H}_{10} \mathrm{~N}_{2}\right)^{2+}$ groups observed at $z / b=1 / 3$. Between organic entities, two water molecules are intercalated. ${ }^{35}$

The main aim of this work is to determine some important optical parameters such as the optical energy gap $\left(E_{g}\right)$, the Urbach energy $\left(E_{u}\right)$ and the absorption coefficient $(\alpha)$. In addition, we have reported in this paper its structure and results of the impedance spectroscopy, the temperature (303$453 \mathrm{~K}$ ) and frequency dependence of the electrical conductivity and the dielectric properties of the sample.

\section{Experimental Section}

\subsection{Synthesis}

All reagents were collected from commercial and manipled sources without purification. Colorless single crystals of $\left(\mathrm{C}_{6} \mathrm{H}_{10} \mathrm{~N}_{2}\right)\left(\mathrm{Hg}_{2} \mathrm{Cl}_{5}\right)_{2} .3 \mathrm{H}_{2} \mathrm{O}$ was prepared by hydrothermal methods with the following steps: at first, each reactant, mercury chloride $(32.5 \%)$ and 1, 2-benzen diammonium $(67.5 \%)$, is dissolved in the dilute aqueous solution of $\mathrm{HCl}(37 \%)$, (molar ratio 1:4) for a few minutes. Second, such solutions were slowly combined in an autoclave and kept at $85^{\circ} \mathrm{C}$ under autogenous pressure for $24 \mathrm{~h}$. After cooling to room temperature, colorless single crystals

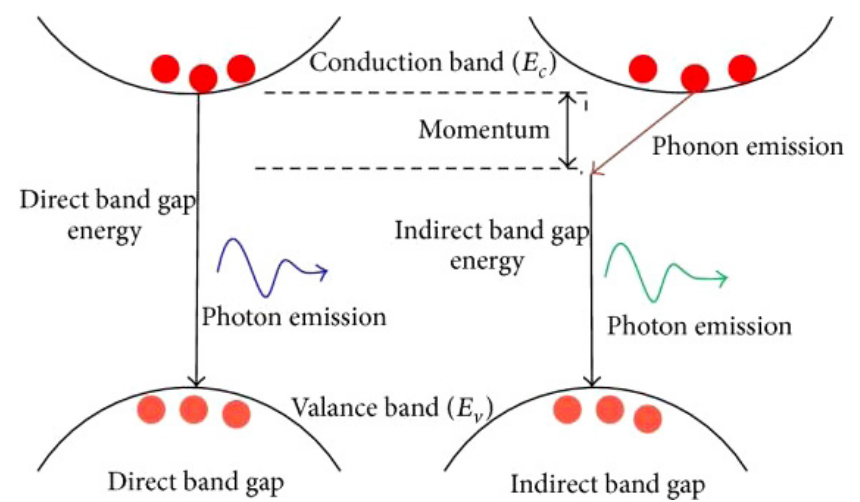

Fig. 1. The difference between direct and indirect band gap. formed. Schematically, the reaction is shown in the following equation:

$$
\mathrm{C}_{6} \mathrm{H}_{8} \mathrm{~N}_{2}+4 \mathrm{HgCl}_{2}\left(\stackrel{\mathrm{HCl} \text { diluted }}{\longrightarrow}\left(\mathrm{C}_{6} \mathrm{H}_{10} \mathrm{~N}_{2}\right)\left(\mathrm{Hg}_{2} \mathrm{Cl}_{5}\right)_{2}\right. \text {. }
$$
$3 \mathrm{H}_{2} \mathrm{O}$.

\subsection{Characterization}

\subsubsection{Optical measurements}

The optical measurements, in the UV-visible liquid range was made using a spectrophotometer, Cary-Varian spectrophotometer, within a (200-800 nm) wavelength range. The UV-visible solid was recorded at room temperature with a spectrophotometer, JENWAY 6400 , in a wavelength range (320-1000 nm).

The analysis was carried out on solid crystals. Thereafter, these crystals are dissolved in aqueous solutions obtained by the dilution of hydrochloric acid $(\mathrm{HCl})$ with different concentrations.

\subsubsection{Dielectrical measurements}

To estimate the electrical and dielectrical proprieties, the $\left(\mathrm{C}_{6} \mathrm{H}_{10} \mathrm{~N}_{2}\right)\left(\mathrm{Hg}_{2} \mathrm{Cl}_{5}\right)_{2} .3 \mathrm{H}_{2} \mathrm{O}$ powder was pressed at $5 \mathrm{t} \mathrm{cm}^{-2}$ ton pressure, forming a pallet of about $8 \mathrm{~mm}$ diameter and about $1.2 \mathrm{~mm}$ thickness. The pellet disc has been preserved with Ag paste to supply good electrical contact. All electrical measurements of real and imaginary components of the impedance parameters $\left(Z^{\prime}\right.$ and $\left.Z^{\prime \prime}\right)$ were made over a wide range of temperature $(303-453 \mathrm{~K})$ and frequency $(200 \mathrm{~Hz}$ to $1 \mathrm{MHz}$ ) using a Tegam 3550 impedance analyzer interfaced to a compatible computer.

\section{Results and Discussion}

\subsection{Absorbance spectra liquid}

The optical measurement was carried out in the range 200$800 \mathrm{~nm}$, as reported in Fig. 2. As seen, there are five distinct absorption peaks at 300, 466, 496, 560 and $670 \mathrm{~nm}$. In hybrid compounds based on aromatic ring, the $\pi-\pi^{*}$ transition of the benzenoid ring is observed around $319 \mathrm{~nm}$, this result is in agreement with similar compounds $(\lambda=$ average $300 \mathrm{~nm})^{36,37}$

Additionally, the observed absorptions at 466, 496, 560 and $615 \mathrm{~nm}$ are caused by band gap absorption and they are attributed to the excitation of free electron-hole pairs within the $\left[\mathrm{Hg}_{2} \mathrm{Cl}_{5}\right]^{-}$inorganic chain.

These peaks are mostly due to a photoinduced exciton constituted relative to the transition from the top of the valence band, including of $\mathrm{Cl}(3 \mathrm{p})$ orbital to the bottom of the $\mathrm{Hg}(6 \mathrm{~s})$ conduction band (absorption between $\mathrm{Cl}(3 \mathrm{p})$ and $\mathrm{Hg}$ (6s) (band to band)) (Fig. 3). ${ }^{38-40}$ Indeed, the electrons 


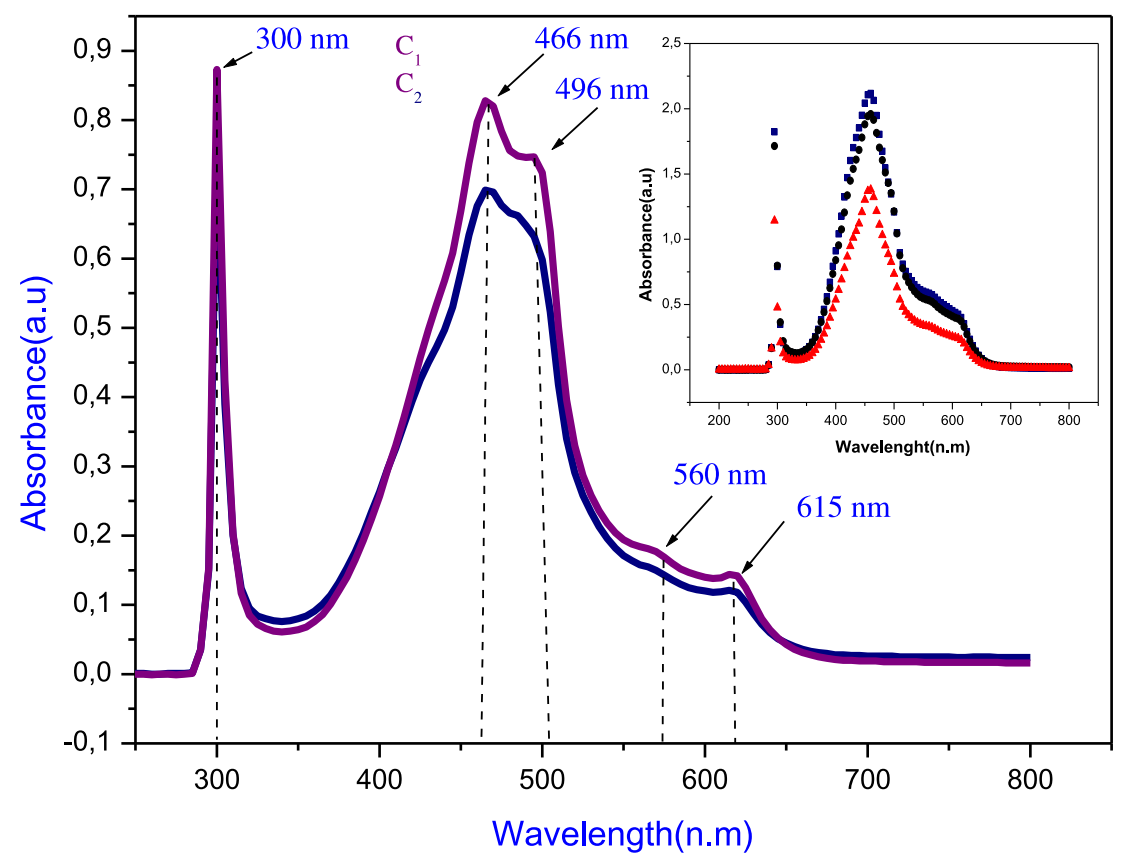

Fig. 2. Liquid-state UV-Vis spectrum of $\left(\mathrm{C}_{6} \mathrm{H}_{10} \mathrm{~N}_{2}\right)\left(\mathrm{Hg}_{2} \mathrm{Cl}_{5}\right)_{2} \cdot 3 \mathrm{H}_{2} \mathrm{O}$ measured at room temperature.

Excitation

VB

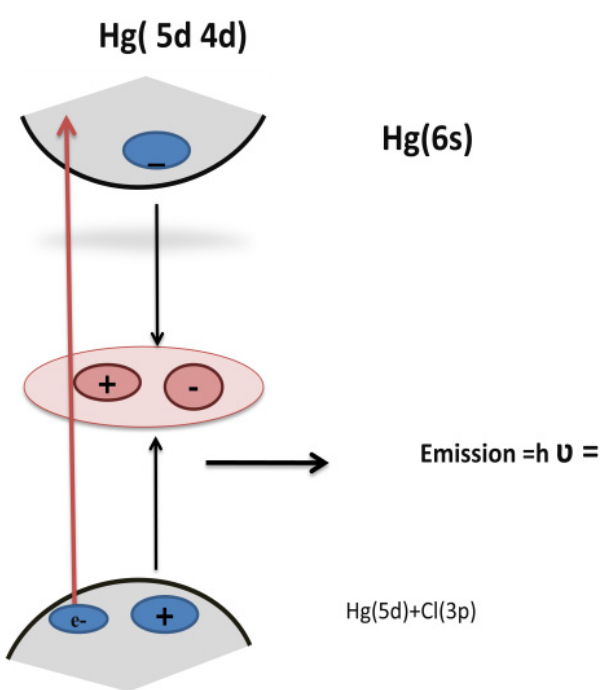

Fig. 3. Simple model for the formation and recombination of the exciton in $\left(\mathrm{C}_{6} \mathrm{H}_{10} \mathrm{~N}_{2}\right)\left(\mathrm{Hg}_{2} \mathrm{Cl}_{5}\right)_{2} .3 \mathrm{H}_{2} \mathrm{O}$ material.

responsible for the electronic transition are both seen as having low energy and confirmed the good stability of crystal.

\subsection{Absorbance spectra solid}

The optical absorption of the synthesized compound $\left(\mathrm{C}_{6} \mathrm{H}_{10} \mathrm{~N}_{2}\right)\left(\mathrm{Hg}_{2} \mathrm{Cl}_{5}\right)_{2} \cdot 3 \mathrm{H}_{2} \mathrm{O}$ is shown in Fig. 4. The latter exhibited seven absorption peaks in the visible region and in the near IR region at 239, 278, 302, 380, 422, 560 and

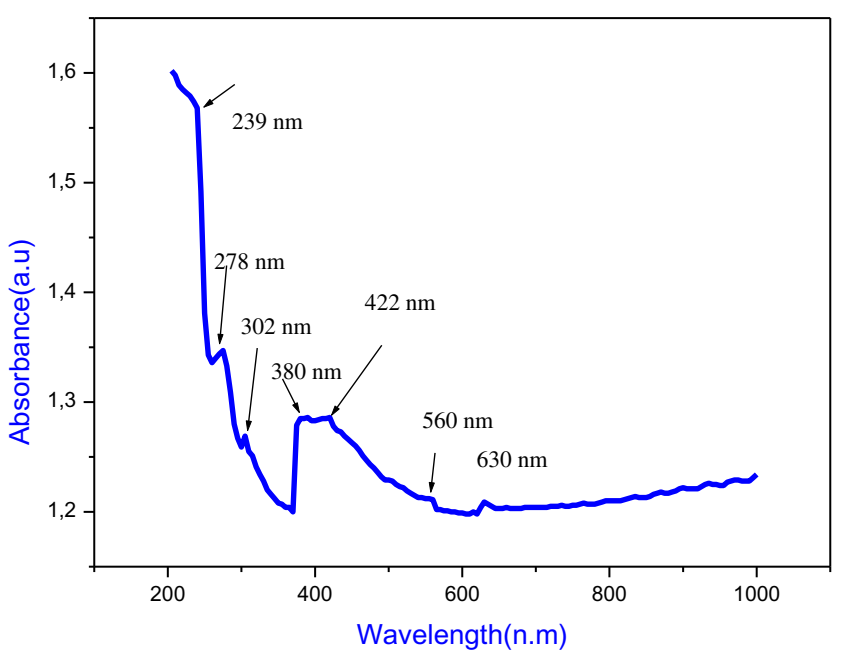

Fig. 4. Solid-state UV-Vis spectrum of $\left(\mathrm{C}_{6} \mathrm{H}_{10} \mathrm{~N}_{2}\right)\left(\mathrm{Hg}_{2} \mathrm{Cl}_{5}\right)_{2} \cdot 3 \mathrm{H}_{2} \mathrm{O}$.

$630 \mathrm{~nm}$, respectively. The highest energy absorption peaks at 422, 560 and $630 \mathrm{~nm}$ are due to a photoinduced exciton formed by the transition from the top of the valence band consisting of $\mathrm{Cl}(3 \mathrm{p})$ orbital to the bottom of the $\mathrm{Hg}$ (6s) conduction band. ${ }^{36,37,40}$ The bands with maximum energies at 239, 278, 302 and $380 \mathrm{~nm}$ can be assigned to the absorption of a highest energetic level in the conduction band.

The main aim is to determine some important optical constants such as the optical absorption coefficient $\alpha$, the band gap, the Urbach energy. The object is to develop an understanding of the relationship of measurable optical properties to the dielectric function of this title compound. 


\subsection{Optical band gap}

The optical absorption edge is a significant parameter for describing solid-state materials. Also, for disordered materials it is interpreted in terms of direct or indirect transition through an optical band gap. The absorption coefficient $(\alpha)$ is a very important parameter for optical applications. The absorption coefficient $(\alpha)$ is calculated by using the formula $(1)^{41}$ :

$$
\alpha=\frac{2.303 A}{d}
$$

where $A$ is the absorbance and $d$ is the thickness of the pellet.

The optical band gap $\left(E_{g}\right)$ is related to absorption coefficient $(\alpha)$ and photon energy $(h v)$ through the Tauc relation ${ }^{42}$ :

$$
(\alpha h v)=B\left(h v-E_{g}\right)^{n}
$$

where $B$ is constant, $h v$ is the photon energy, $E_{g}$ is an optical band gap and $n$ is the index, which takes different values depending on the mechanism of interband transitions $n=2$ and $1 / 2$ corresponding to indirect and direct transitions, respectively. Figure 5 shows the plot of $(\alpha h v) 2$ of optical liquid and Fig. 6 shows the plots of $(\alpha h v)^{1 / 2}$ and $(\alpha h v)^{2}$ of optical solid as a function of photon energy $(h v)$ for $\left(\mathrm{C}_{6} \mathrm{H}_{10} \mathrm{~N}_{2}\right)$ $\left(\mathrm{Hg}_{2} \mathrm{Cl}_{5}\right)_{2} .3 \mathrm{H}_{2} \mathrm{O}$ compound. The $E_{g}$ value of $\left(\mathrm{C}_{6} \mathrm{H}_{10} \mathrm{~N}_{2}\right)$ $\left(\mathrm{Hg}_{2} \mathrm{Cl}_{5}\right)_{2} \cdot 3 \mathrm{H}_{2} \mathrm{O}$ compound is obtained from the intersection of extrapolation of the linear part of the curve with the $x$-axis. As can be seen clearly from Figs. 5 and 6, the best fit is obtained for $n=2$. Therefore, the transition is indirect and the optical band gap value is found to be $(2.37 \mathrm{eV})$ for liquid and $(4.33 \mathrm{eV})$ for solid.

\subsection{Urbach energy $E_{u}$}

The Urbach energy $E_{u}$ is a very important parameter to characterize the disorder of a material. It corresponds to transitions between extended states of the valence band and

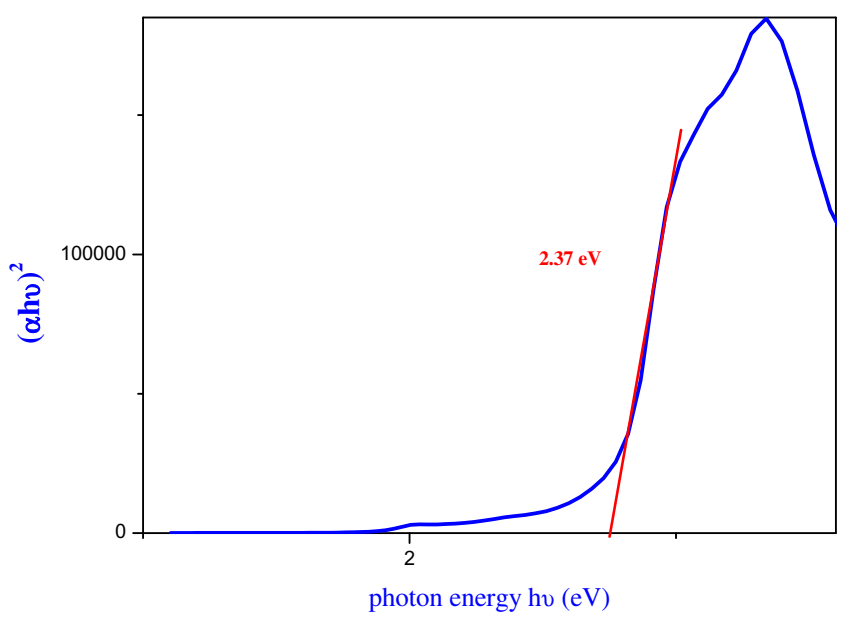

Fig. 5. Plots $(\alpha h v)^{2}$ versus $h v$ for liquid solution of $\left(\mathrm{C}_{6} \mathrm{H}_{10} \mathrm{~N}_{2}\right)$ $\left(\mathrm{Hg}_{2} \mathrm{Cl}_{5}\right)_{2} \cdot 3 \mathrm{H}_{2} \mathrm{O}$.

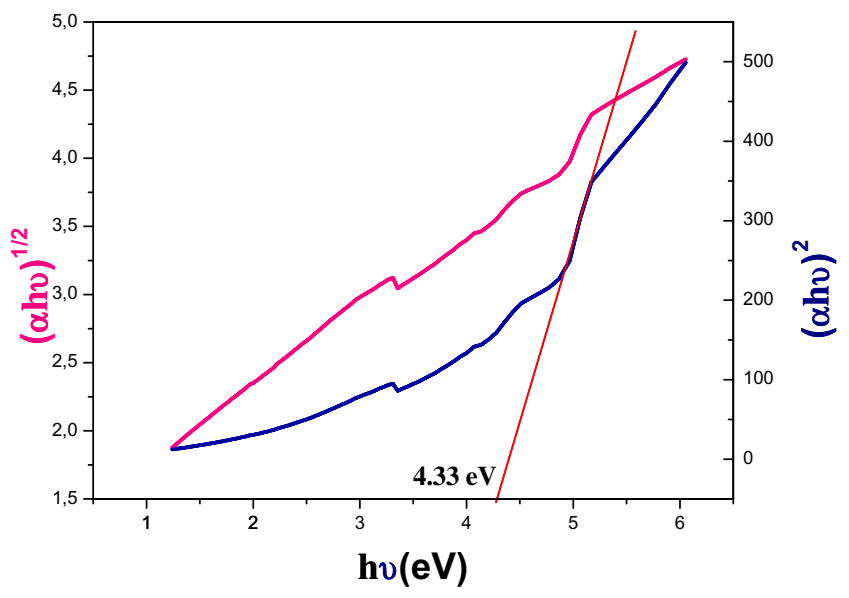

Fig. 6. Direct and indirect band gap for the solid crystal.

localized states of the conduction band. Bougrine et al. ${ }^{43}$ interpreted the Urbach energy, $E_{u}$, as the width of the band's localized states in the band gap. From the variation of the absorption coefficient it is possible to deduce the disorder in the compound. In the low photon energy range $\left(h v<E_{g}\right)$, the absorption coefficient can be explained by Urbach Relation $^{44}$ :

$$
\alpha=\alpha_{0} \exp \left(\frac{h v}{E_{u}}\right)
$$

where $\alpha_{0}$ is a constant and $E_{u}$ is the Urbach energy.

The Urbach energy is obtained from the plot of $\ln (\alpha)$ versus photon energy ( $h v$ ) which is deduced from the reciprocal of the slope of the linear part seen in Figs. 7(a) and 7(b). The estimated values are presented in Table 1 . The values prove the presence of disorder in this hybrid compound. In fact, the Urbach energy is associated with the micro-structural lattice disorder. ${ }^{45}$

\subsection{The absorption coefficient}

The absorption coefficient $(\alpha)$ which is defined as the decrement ratio of incident radiation relative to unit length in the direction of wave propagation in the medium is related to the absorbance $(A)$ through the relation:

$$
\alpha=\frac{2.303 A}{d} .
$$

The variation of absorption coefficient $\alpha$ of our samples as a function of wavelength is shown in Fig. 8. It is clearly seen from the figure that the absorption coefficient shows a variable change as a function of wavelength. The absorption has its minimum at low energy and increases with high optical energy in a manner similar to the absorption edge of the semiconductors. 


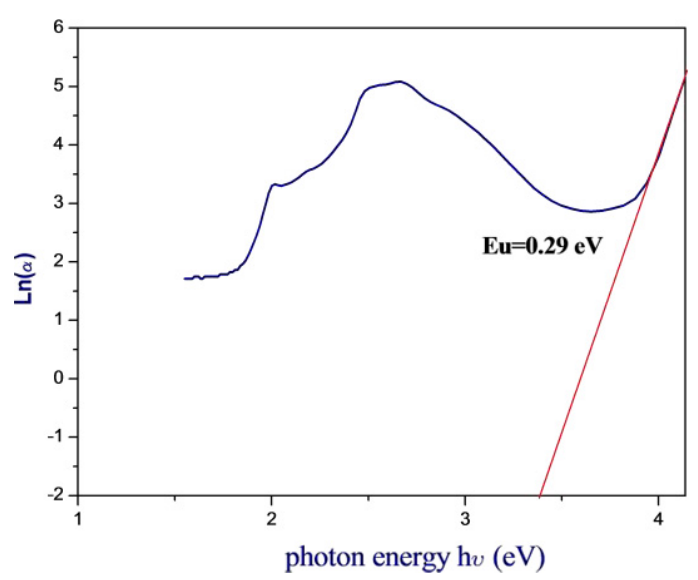

(a)

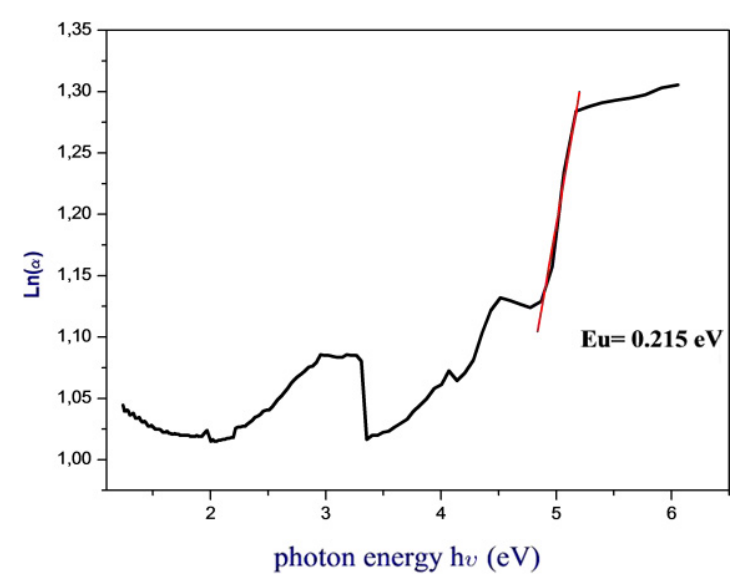

(b)

Fig. 7. (a, b) The logarithmic variation of the absorption coefficient versus photon energy for the liquid solution and solid crystal, respectively.

Table 1. Values of gap energy and Urbach energy for $\left(\mathrm{C}_{6} \mathrm{H}_{10} \mathrm{~N}_{2}\right)\left(\mathrm{Hg}_{2} \mathrm{Cl}_{5}\right)_{2} \cdot 3 \mathrm{H}_{2} \mathrm{O}$.

\begin{tabular}{lcl}
\hline & $E_{g}(\mathrm{eV})$ & $E_{u}(\mathrm{eV})$ \\
\hline Liquid & 2.37 & 0.29 \\
Solid & 4.33 & 0.215 \\
\hline
\end{tabular}

\section{Electrical Properties}

It is worthy to note that complex impedance spectroscopy is a very effective technique to examine the electrical and dielectric properties of hybrid organic-inorganic halide materials.

It is based on modeling the frequency response of the sample by an electrical circuit, which reflects the resistance and capacitive character of the material. In addition, the intention of this process is a useful method to resolve the contributions of various processes such as bulk, grain

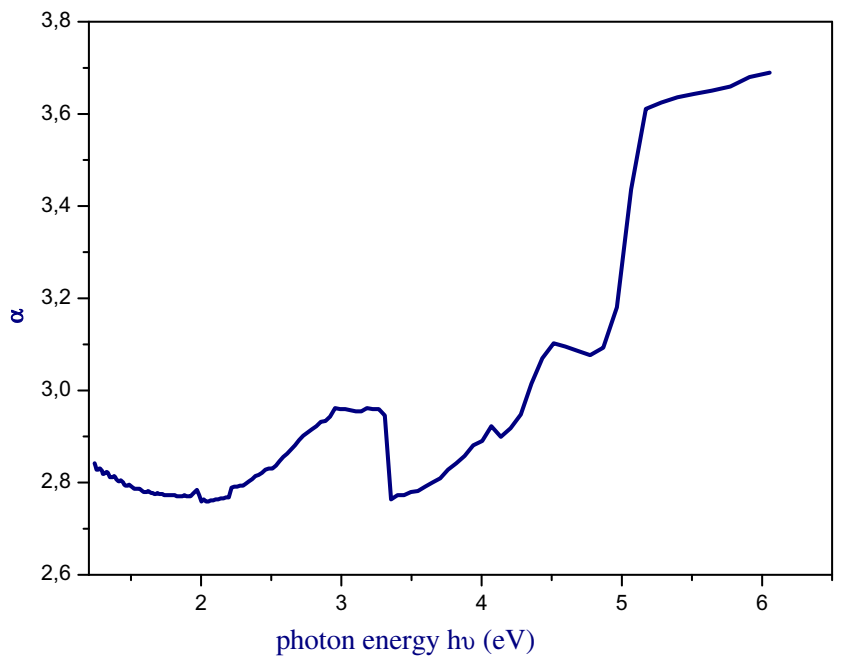

Fig. 8. Variation of absorption coefficient of the sample as a function of wavelength.

boundary, and electrode effect in the specified frequency domain. $^{46}$ This technique is widely applied to systems modeled by an equivalent circuit to determine their dynamic (AC) characteristics from which physical parameters of the system can be calculated.

With respect to complex impedance data, $Z$, it can be represented by its real, $Z^{\prime}$, and imaginary, $Z^{\prime \prime}$, parts of the relation $Z^{*}=Z^{\prime}-i Z^{\prime}$.

\subsection{Impedance analysis and equivalent circuit}

The Nyquist plots ( $-Z^{\prime \prime}$ versus $Z^{\prime}$ ) of the compound at different temperatures $303 \mathrm{~K} \leq T \leq 453 \mathrm{~K}$ are reported in Fig. 9. The spectra prove that there are typical semicircles, whose center lies below the abscise axe by an angle $(\alpha \pi) / 2$. This undoubtedly confirms the Cole-Cole type of relaxation. $^{47}$

The impedance results are analyzed using ZView software and the best fit is obtained when using an equivalent circuit. The complex impedance spectra are modeled by equivalent circuit which is formed by two cells connected in series, the first being formed by a parallel combination of bulk resistance $R 1$, capacitance $C$, in series with a parallel combination of resistance, capacity and fractal capacity constant phase element (CPE). The second is formed by combination of bulk boundary resistance $R 2$, capacitance $C 2$, and fractal capacity CPE.

The theoretical values of the real $\left(Z^{\prime}\right)$ and imaginary $\left(-Z^{\prime \prime}\right)$ components of the impedance are calculated using expressions $(1,2)$ derived from the chosen equivalent circuit.

$$
\begin{aligned}
Z^{\prime}= & \frac{R_{1}+R_{1}^{2} Q_{1} W^{\alpha 1} \cos \left(\alpha_{1} \pi / 2\right)}{\left(1+R_{1} Q_{1} W^{\alpha 1} \cos \left(\alpha_{1} \pi / 2\right)\right)^{2}+\left(R_{1} Q_{1} W^{\alpha 1} \sin \left(\alpha_{1} \pi / 2\right)\right)^{2}} \\
& +\frac{R_{2}+R_{2}^{2} Q_{2} W^{\alpha 2} \cos \left(\alpha_{2} \pi / 2\right)}{\left(1+R_{2} Q_{2} W^{\alpha 2} \cos \left(\alpha_{2} \pi / 2\right)\right)^{2}+\left(R_{2} Q_{2} W^{\alpha 2} \sin \left(\alpha_{2} \pi / 2\right)\right)^{2}},
\end{aligned}
$$




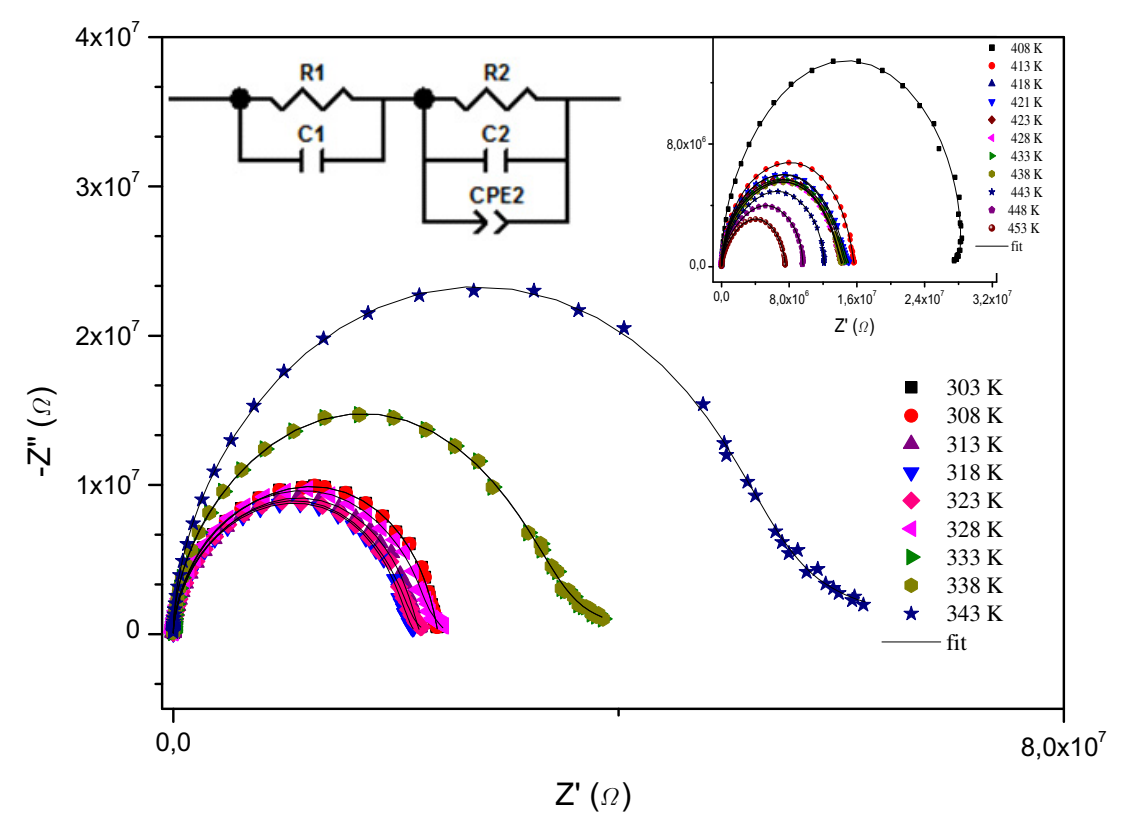

Fig. 9. Nyquist plots as a function of temperature of $\left(\mathrm{C}_{6} \mathrm{H}_{10} \mathrm{~N}_{2}\right)\left(\mathrm{Hg}_{2} \mathrm{Cl}_{5}\right)_{2} \cdot 3 \mathrm{H}_{2} \mathrm{O}$.

$$
\begin{aligned}
-Z^{\prime \prime}= & \frac{R_{1}^{2} Q_{1} W^{\alpha 1} \sin \left(\alpha_{1} \pi / 2\right)}{\left(1+R_{1} Q_{1} W^{\alpha 1} \cos \left(\alpha_{1} \pi / 2\right)\right)^{2}+\left(R_{1} Q_{1} W^{\alpha 1} \sin \left(\alpha_{1} \pi / 2\right)\right)^{2}} \\
& +\frac{R_{2}^{2} Q_{2} W^{\alpha 2} \sin \left(\alpha_{2} \pi / 2\right)}{\left(1+R_{2} Q_{2} W^{\alpha 2} \cos \left(\alpha_{2} \pi / 2\right)\right)^{2}+\left(R_{2} Q_{2} W^{\alpha 2} \sin \left(\alpha_{2} \pi / 2\right)\right)^{2}} .
\end{aligned}
$$

In order to check the validity of the equivalent circuit, experimental and calculated curves of real $\left(Z^{\prime}\right)$ and imaginary $\left(Z^{\prime \prime}\right)$ parts versus frequency for each compound at selected temperature $323 \mathrm{~K}$ are superposed, Fig. 10. As the frequency increases, $-Z^{\prime \prime}$ increases, whereas

$Z^{\prime}$ decreases, this trend continues up to a particular frequency which in $-Z^{\prime \prime}$ occupies a maximum value and in $Z^{\prime}$ intersects.

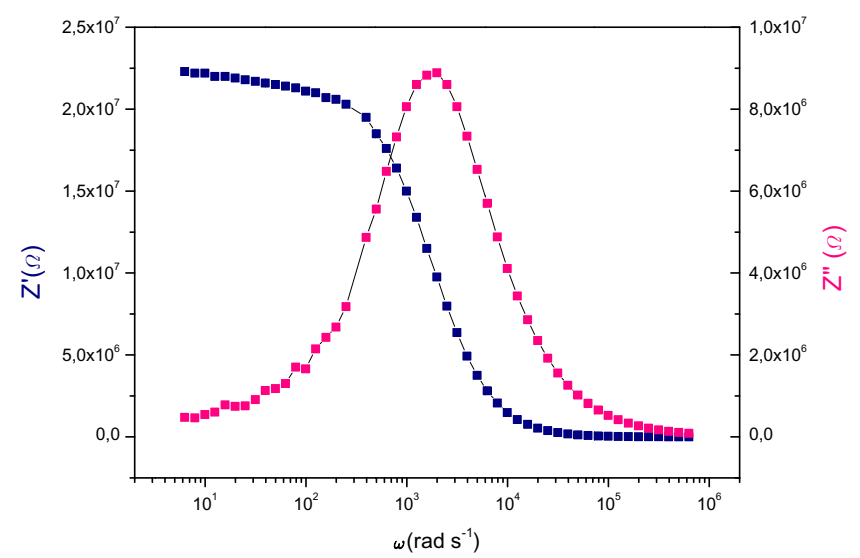

Fig. 10. Variation of $\left(Z^{\prime}\right)$ and $\left(Z^{\prime \prime}\right)$ as function of the angular frequency at $323 \mathrm{~K}$.

\subsection{Conductivity analysis}

\subsubsection{Ac conductivity}

The Ac conductivity has been calculated from the real and the imaginary parts of the impedance data measured over a study range of temperatures. The plot of $\sigma_{A C}$ versus angular frequency $(\omega)$ at different temperatures is given in Fig. 11, it is generally analyzed using the following equation $^{48}$ :

$$
\sigma_{\mathrm{AC}}(\omega)=\frac{\sigma_{s}}{1+\tau^{2} \omega^{2}}+\frac{\sigma_{\infty} \tau^{2} \omega^{2}}{1+\tau^{2} \omega^{2}}+A \omega^{n},
$$

where $\sigma_{s}$ is the conductivity at low-frequencies, $\sigma_{\infty}$ is an estimate of conductivity at high-frequencies, $A$ are temperature-dependent parameters and $s$ is the power exponent. $\omega=2 \pi f$ is the angular frequency, $\tau$ is the characteristic relaxation time and $s$ is an exponent dependent on frequency and temperature, which lies between 0 and 1 .

The AC conductivity of the hybrid material at different temperature is usually described by the presence of two plateaus separated by a frequency dispersive region are observed in the pattern. The low-frequency plateau (part (a)) Fig. 11 represents the total conductivity whereas the highfrequency plateau (part (b)) Fig. 11 represents the contribution of grains to the total conductivity. ${ }^{49-51}$ The abovementioned equation has been used to fit the AC conductivity data.

The temperature dependence of AC conductivity for the compound at different frequencies is given in Fig. 12. 


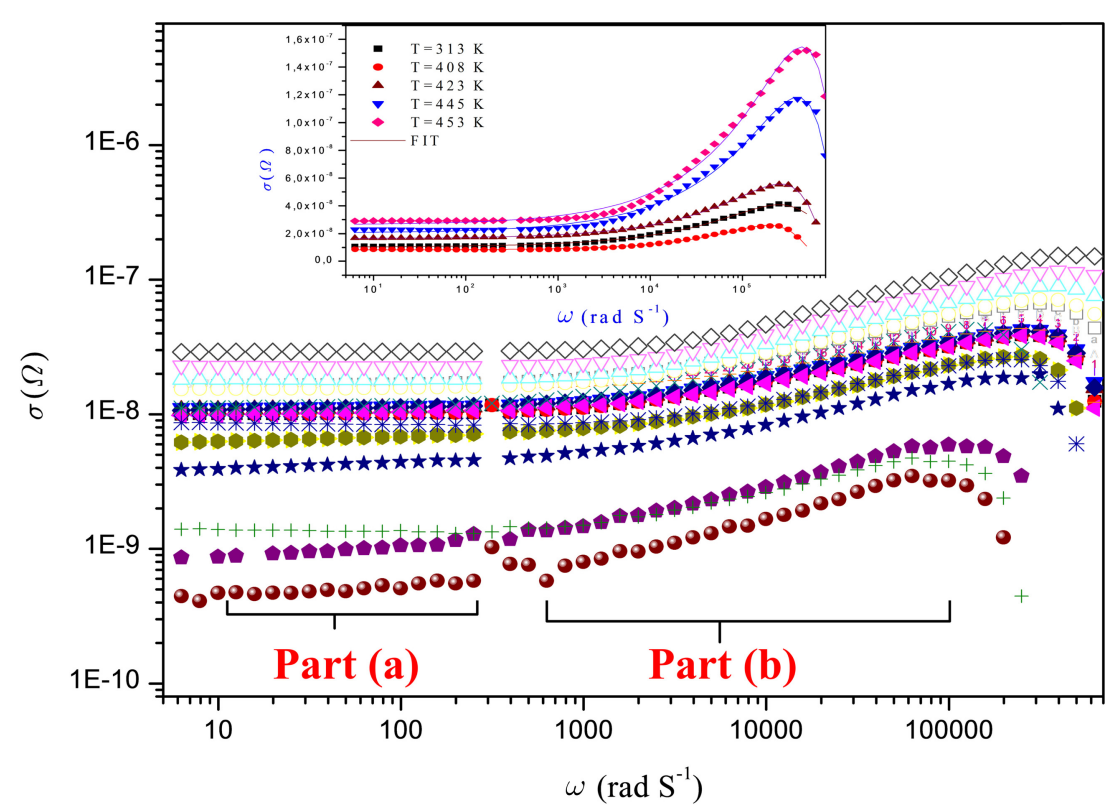

Fig. 11. Frequency dependence of AC conductivity at various temperatures.

The logarithmic variation of the AC conductivity with temperature at different frequencies is illustrated in Fig. 13. The conductivities increase with the inverse of the absolute temperature.

\section{Complex Dielectric Modulus Analysis}

A complex electric modulus plot is often a used tool to determine, give more importance to the elements with the smallest capacitance occurring in the dielectric system, analyze and interpret the dynamical aspects of electrical transport phenomena. ${ }^{58}$ This formalism permits to discriminate against electrode polarization and grain boundary conduction mechanism. ${ }^{59,60}$

The electric modulus $\left(M^{*}\right)$ can be described by the reciprocal of the complex permittivity ${ }^{61}$ and corresponds to the relaxation of the electric field in the system when the electric displacement is constant.

$$
M^{*}(\omega)=\frac{1}{\varepsilon^{*}(\omega)}=i\left(\omega C_{0}\right) Z^{*}=M^{\prime}-i M^{\prime \prime},
$$

where $M^{\prime}$ and $M^{\prime \prime}$ are the real and imaginary parts of the complex modulus.

The variation of $M^{\prime}$ as a function of the frequency at various temperature is shown in Fig. 14. At lower frequencies, $M^{\prime}$ tends to be very small, confirming that the electrode effects make a negligible contribution and hence may be ignored when the data are analyzed in modulus representation. It is also characterized by a very low value $(\sim 0)$ of $M^{\prime}$ in the low-frequency region. A continuous dispersion with the increase in frequency has a tendency to saturate at a maximum asymptotic value designated by $M_{\infty}$, in the high-frequency region for all temperatures. This is due to the relaxation processes that are spread over a range of frequencies. Such observations may possibly be related to lack of restoring force governing the mobility of charge carriers under the action of an induced electric field. This behavior supports long-range mobility of charge carriers. Furthermore, a sigmoidal increase in the value of $M^{\prime}$ with an increasing frequency approaching ultimately to $M_{\infty}$ may be attributed to the conduction phenomenon due to the short-range mobility of charge carriers.

Figure 15 shows the variation of the imaginary part $M^{\prime \prime}$ of the complex modulus as a function of angular frequency at different temperatures. These curves are characterized by the presence of two relaxation peaks. Two relaxation peaks are observed. Thus, the smaller peak at lower frequency is associated to the grain boundary effect, while the welldefined one at higher frequency is correlated with the bulk effects. The general method to check the nature of the dielectric relaxation in the solid is to fit the measured data by Kohlrausch-Williams-Watts (KWW) decay function. ${ }^{62}$

We have fitted the imaginary parts of the electric modulus for different temperatures with an approximate frequency representation of KWW function, proposed recently by Bergman:

$$
\begin{aligned}
M^{\prime \prime}= & \frac{M_{1 \text { max }}^{\prime \prime}}{\left(\left(1-\beta_{1}\right)+\left(\frac{\beta_{1}}{1+\beta_{1}}\right)\right)\left[\left(\frac{\omega_{1 \max }}{\omega}\right)+\left(\frac{\omega}{\omega_{1 \max }}\right)^{\beta_{1}}\right]} \\
& +\frac{M_{2 \max }^{\prime \prime}}{\left(\left(1-\beta_{2}\right)+\left(\frac{\beta_{2}}{1+\beta_{2}}\right)\right)\left[\left(\frac{\omega_{2 \max }}{\omega}\right)+\left(\frac{\omega}{\omega_{2 \max }}\right)^{\beta_{2}}\right]},
\end{aligned}
$$

where $M^{\prime \prime}$ max and $\omega_{\max }$ are the peak maximum and the peak angular frequency of the imaginary part of the modulus, respectively. To account for the grain boundary effects, our 

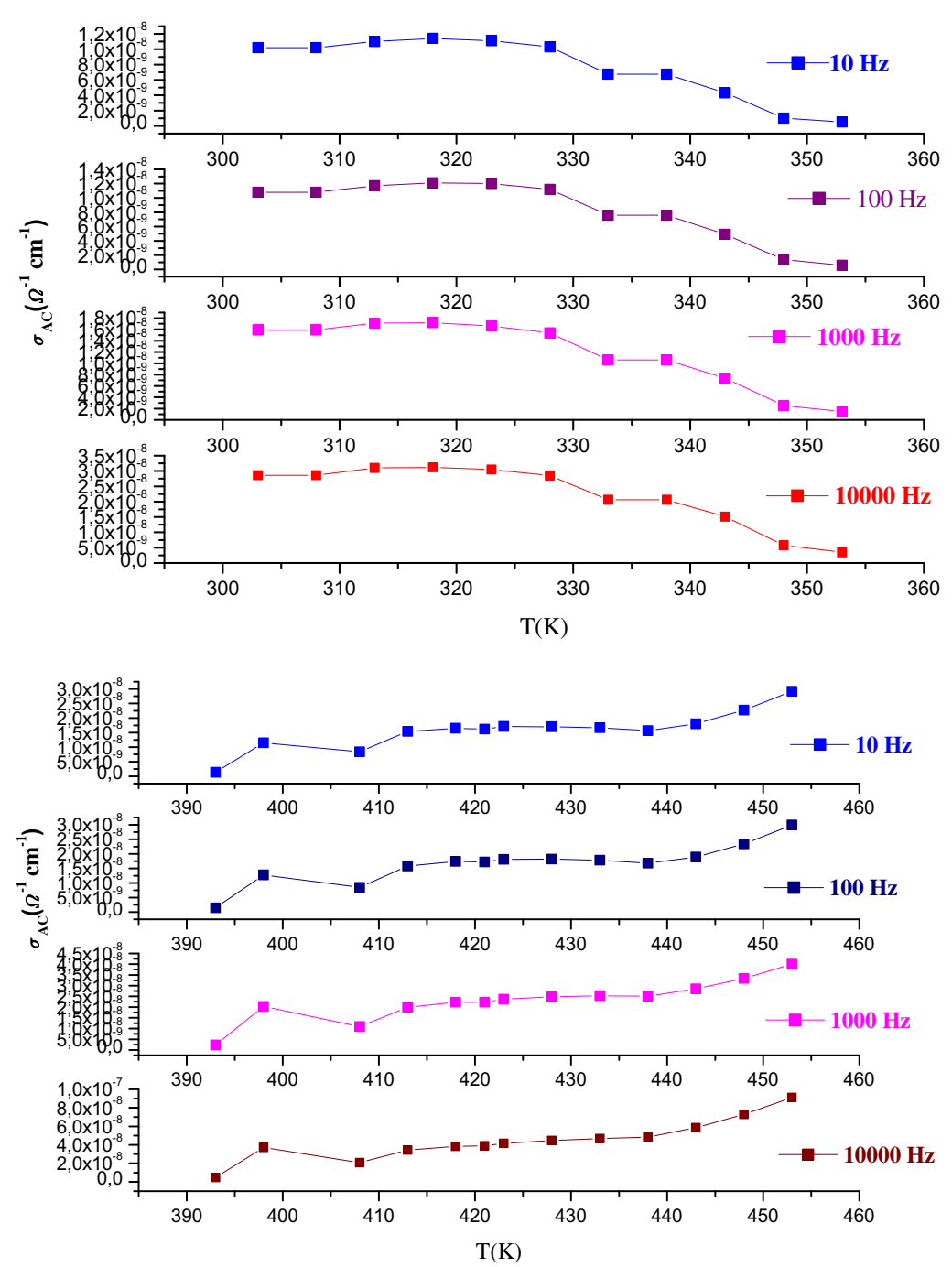

Fig. 12. The temperature dependence of AC conductivity for the compound at different frequencies.

experimental data have been fitted to the double Bergman's equation

$$
\varphi(t)=\exp \left(-\left(\left(\frac{t}{\tau}\right)^{\beta}\right)\right)
$$

where $\tau$ is the characteristic relaxation time and $\beta$ is the wellknown Kohlrausch parameter, which decreases with an increase in the relaxation time distribution. The value of the Kohlrausch parameter for a practical solid electrolyte is clearly less than 1 .

In this case, the $\beta_{1}$ and $\beta_{2}$ values are temperature-dependent (Fig. 16). We can say that the interactions between the load carriers vary with the temperature.

\section{Frequency and Temperature Dependence of the Dielectric Properties}

The study of the dielectric properties $\left(\varepsilon^{\prime}, \varepsilon^{\prime \prime}\right.$ and $\left.\tan \delta\right)$ is an important source of valuable information about conduction processes since the origin and the dielectric losses. ${ }^{52-56}$ The dielectric relaxation is described by a non-Debye model which gives the frequency-dependent complex permittivity. The complex permittivity formalism has been employed to describe the electrical and dielectric properties, and it can be defined by the complex equation $(8)^{57}: \varepsilon^{*}=\varepsilon^{\prime}-j \varepsilon^{\prime \prime}$, where $\varepsilon^{\prime}$ and $\varepsilon^{\prime \prime}$ are the real and the imaginary parts of the dielectric constant, respectively,

where

$$
E^{*}=E_{\infty}+\frac{E_{s}-E_{\infty}}{1+\left(i \frac{\omega}{\omega_{1}}\right)^{1-\alpha}}+\frac{\sigma_{0}}{i \varepsilon_{0} \omega} \cdot .58
$$

The variations of $\varepsilon^{\prime}, \varepsilon^{\prime \prime}$ and $\tan \delta$ with angular frequency at several temperatures from 303 to $453 \mathrm{~K}$ are depicted in Figs. 17, 18 and 19, respectively.

The observed change in dielectric properties can be understood by considering the displacement damage introduced by temperatures in the decrease in the values of $\varepsilon^{\prime}, \varepsilon^{\prime \prime}$ and 

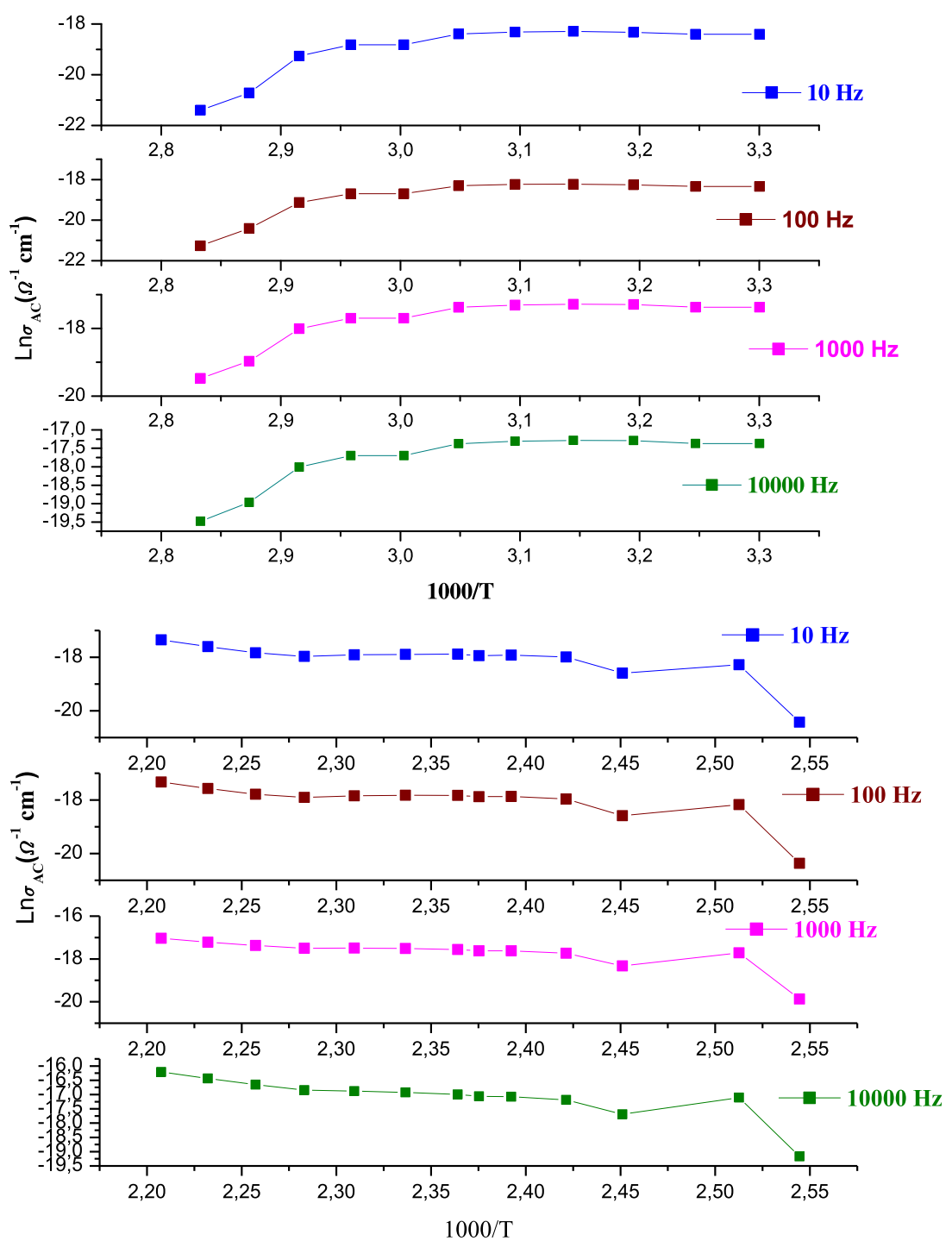

Fig. 13. The logarithmic variation of the AC conductivity with temperature at different frequencies.

$\tan \delta$. It can be seen that the values of $\varepsilon^{\prime}, \varepsilon^{\prime \prime}$ and $\tan \delta$ decrease with increasing temperatures. As mentioned, the decrease in $\varepsilon^{\prime}, \varepsilon^{\prime \prime}$ and $\tan \delta$ with increase in temperature is explained by the fact that as the temperature increases, the interfacial dipoles have less time to orient themselves in the direction of the alternating field. Also, the surface with the semiconductor can easily follow with increasing of conductivity signal at low temperatures and an excess of $\varepsilon^{\prime}, \varepsilon^{\prime \prime}$ and $\tan \delta$ occurs in addition to real dielectric $\varepsilon^{\prime}, \varepsilon^{\prime \prime}$ and tan $\delta$.

The measured impedance data are used to calculate the imaginary $\left(\varepsilon^{\prime \prime}\right)$ parts of the complex dielectric permittivity as $^{59}$ (Eq. (12)):

$\varepsilon^{\prime \prime}(\omega)=\frac{\left(\varepsilon_{s}-\varepsilon_{\infty}\right)\left(\frac{\omega}{\omega_{1}}\right)^{1-\alpha} \sin \left(\frac{(1-\alpha) \pi}{2}\right)}{1+2\left(\frac{\omega}{\omega_{1}}\right)^{1-\alpha} \cos \left(\frac{(1-\alpha) \pi}{2}\right)+\left(\frac{\omega}{\omega_{1}}\right)^{2(1-\alpha)}}+\frac{\sigma_{0}}{\varepsilon_{0} \omega}$.
From Fig. 17, one observes that $\varepsilon^{\prime}$ approaches a limiting constant value, $\varepsilon_{\infty}^{\prime}(\omega)$, at high-frequencies, which can be interpreted as a result of rapid polarization processes with no ionic motion contribution because the frequency is too high and the ions can only oscillate without reaching the sampleelectrode interface. At lower frequencies, the $\varepsilon^{\prime}$ values increase with decreasing frequency with a rapid rise in high temperatures.

From Fig. 18, the variation of the imaginary part of the permittivity with frequency shows that conduction losses predominate at lower frequencies, and hence, at all temperatures the imaginary part of the permittivity $\varepsilon^{\prime \prime}$ shows $1 / \omega$ dependence on angular frequency. Also, $\varepsilon^{\prime \prime}$ increases with increasing temperature, and the dielectric loss peak has not been observed. The common method of getting dielectric loss peak in solid electrolytes is through separating DC conductivity from the total conductivity $\sigma(\omega)$. 


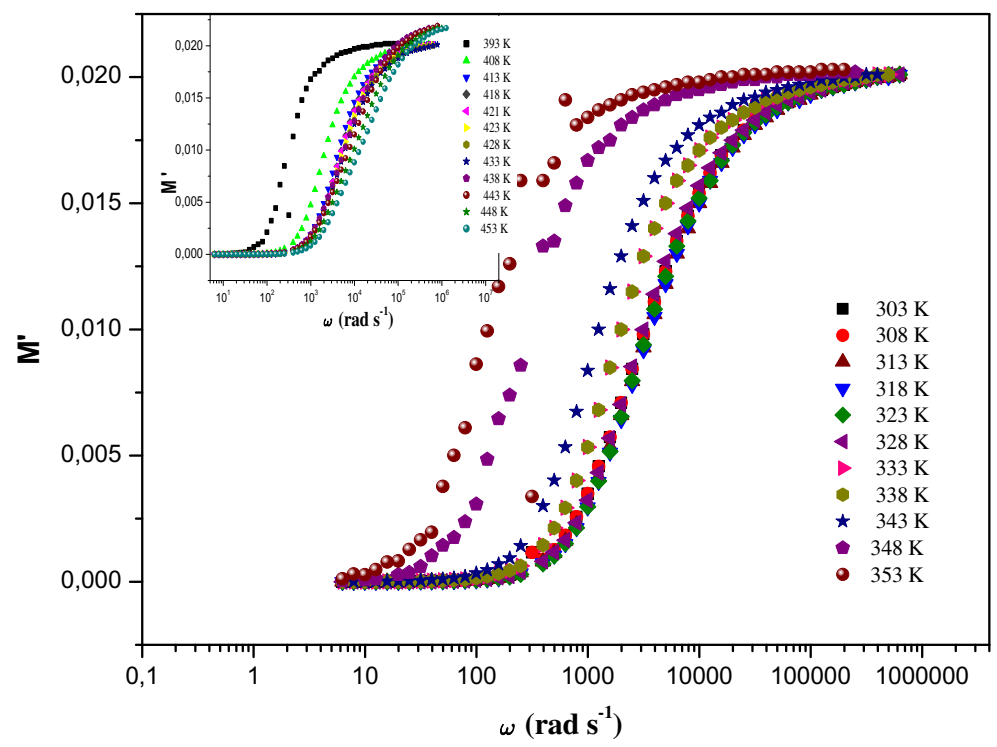

Fig. 14. Variation of the real $M^{\prime}$ of the electric modulus as a function of the frequency at various temperatures.

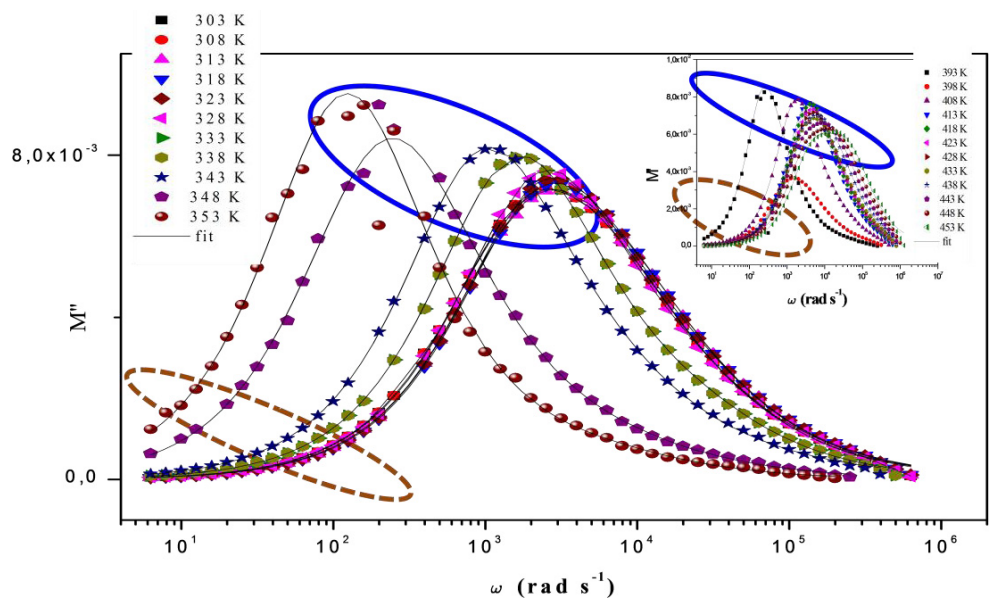

Fig. 15. Frequency dependence of the imaginary part of electric modulus at different temperatures.

The loss factor tangent or dissipation factor $(\tan \delta)$ is given by the ratio of the imaginary $\varepsilon^{\prime \prime}$ and the real $\varepsilon^{\prime}$ parts of the dielectric constant: $\tan (\delta)=\varepsilon^{\prime \prime}(\omega) / \varepsilon^{\prime}(\omega)$ (Fig. 18).

The variation of the loss tangent as a function of frequencies at different temperatures is given in Fig. 18. All the curves show a similar behavior at frequencies above $1 \mathrm{kHz}$. Below $1 \mathrm{kHz}$, an intense increase of dielectric loss was observed for all measurement temperatures. When the temperature increases, there's the creation of defect/disorders (departure of $\mathrm{H}_{2} \mathrm{O}$ ) in the lattice which leads to decreases of the mobility of the majority charge carriers (ions and electrons). At high-frequency, the interfacial dipoles have less time to orient themselves in the direction of the alternating field.

From 343-348 K, a change in the appearance of curves has seen the departure of $\mathrm{H}_{2} \mathrm{O}$ molecules with heating (anhydrous crystal). The pattern of variation is characterized

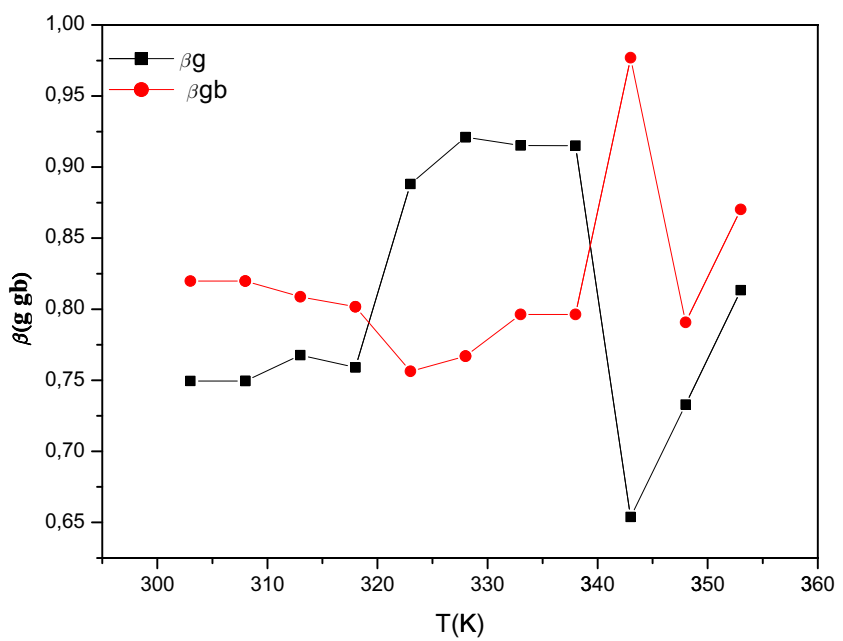

Fig. 16. Temperature dependence of $\beta$ value. 


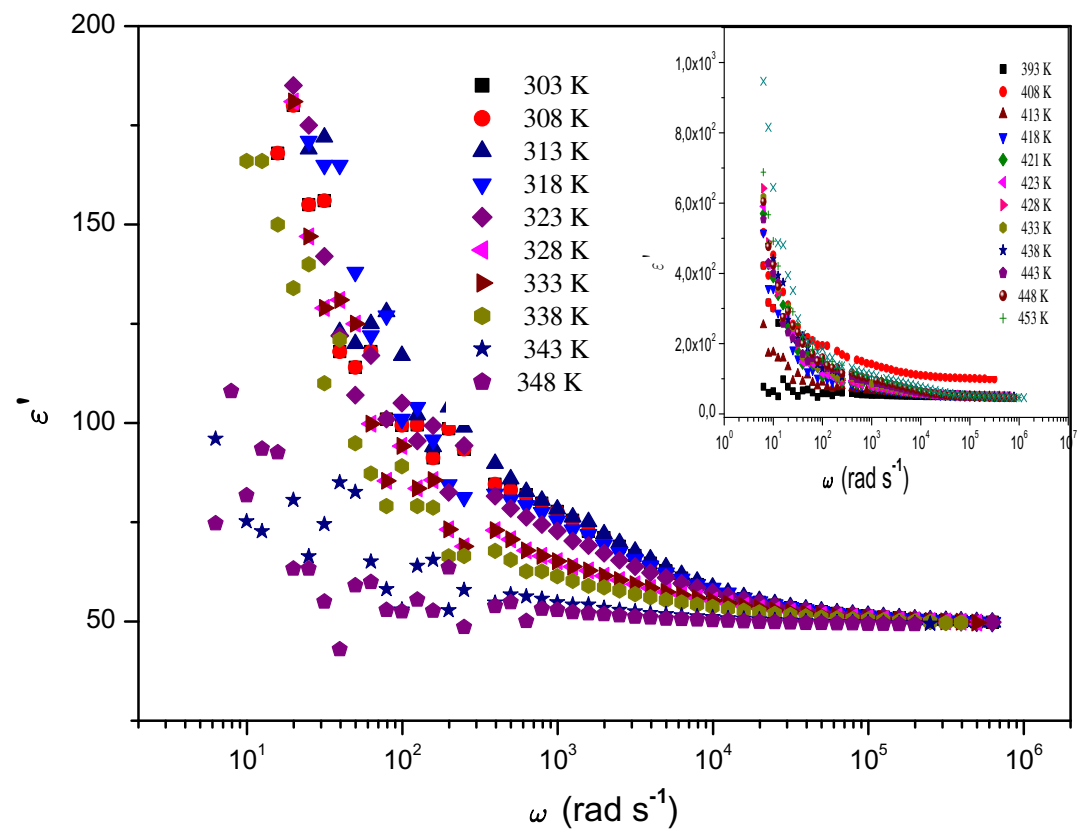

Fig. 17. Frequencies dependence of the real part $\varepsilon^{\prime}$ of complex permittivity at several temperature.

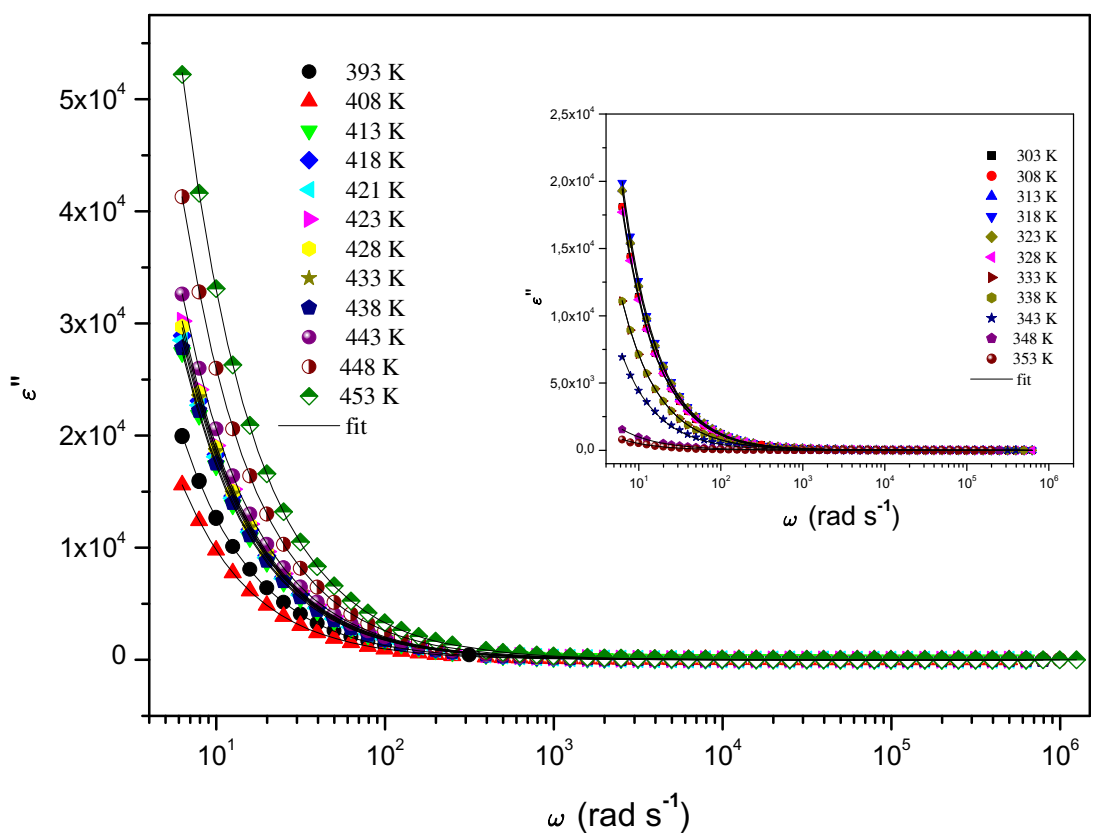

Fig. 18. Frequency dependence of the dielectric loss $\varepsilon^{\prime \prime}(\omega)$ at various temperatures.

by the occurrence of well-defined peaks, which shifts to higher frequencies with increasing temperatures average $400 \mathrm{~K}$. Also, shifting of peaks toward the higher frequency sides with temperature can be attributed to a gradual decrease in resistance with increasing frequency. This type and frequency dependence of $Z^{\prime}$ and $Z^{\prime \prime}$ suggest the presence of dielectric relaxation in the compound. ${ }^{60,61}$

Figures 20 and 21 show the temperature dependence on the real part $\varepsilon^{\prime}$ of permittivity, and the dielectric loss $\varepsilon^{\prime \prime}$ of the compound measured between $10^{3} \mathrm{~Hz}$ and $10 \mathrm{~Hz}$. The variation of the $\varepsilon^{\prime}$ and $\varepsilon^{\prime \prime}$ shows a weak dispersion in the low temperature region. The behavior can be explained by the charge carriers which, on most cases, cannot orient themselves with respect to the direction of applied; therefore, they possess a weak contribution to the polarization and the dielectric behavior. ${ }^{62}$

As the temperature rises, the variation of $\varepsilon^{\prime}$ and $\varepsilon^{\prime \prime}$ increases and shows a strong dispersion. The imperfections/ disorders are created in the lattice and the mobility of the majority charge carriers increases. This may be possibly due 


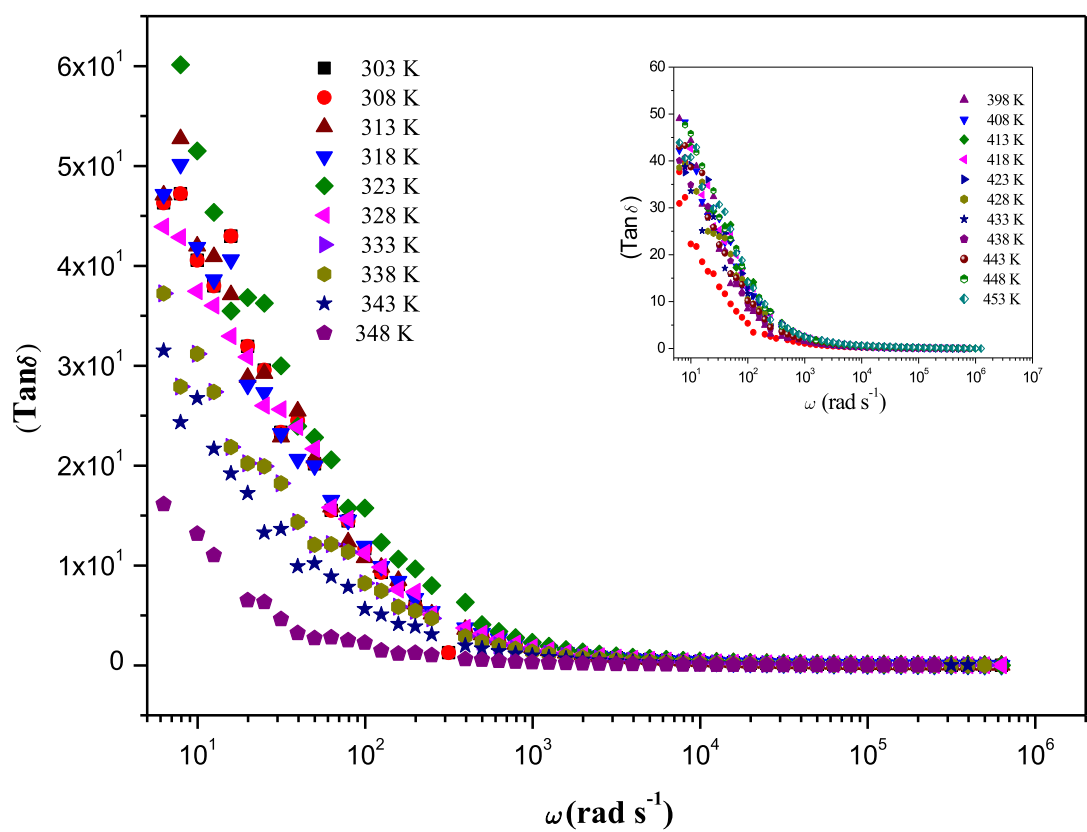

Fig. 19. Variation of the tangent losses $(\tan \delta)$ versus frequency at several temperatures for $\left(\mathrm{C}_{6} \mathrm{H}_{10} \mathrm{~N}_{2}\right)\left(\mathrm{Hg}_{2} \mathrm{Cl}_{5}\right)_{2} .3 \mathrm{H}_{2} \mathrm{O}$ sample.

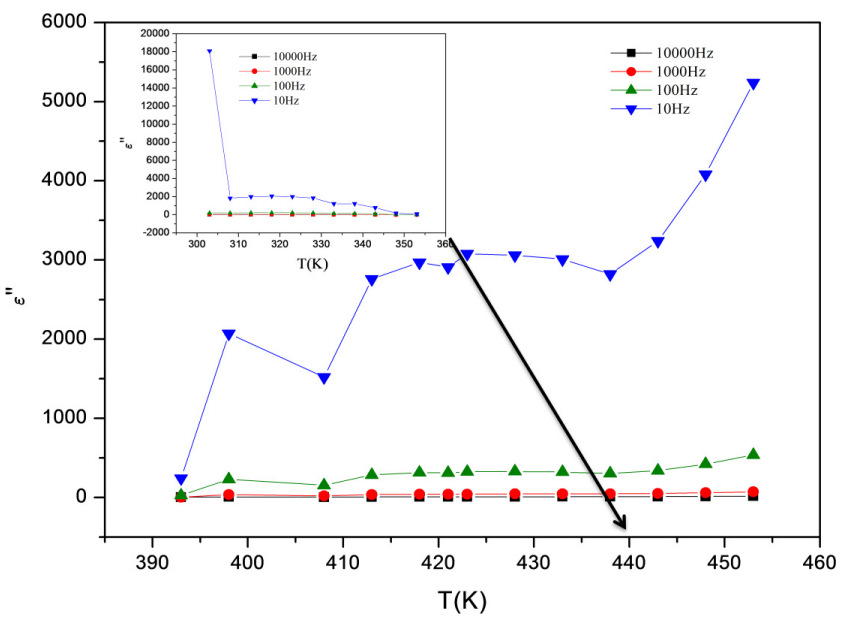

Fig. 20. Variation of the dielectric loss $\varepsilon^{\prime \prime}$ with temperature at different frequencies.

to the ion jump, the orientation, and space charge effect resulting from the increased concentrations of the charge carriers; these results confirm the previous discussion (Fig. 17).

\section{Conclusion}

In summary, the $\left(\mathrm{C}_{6} \mathrm{H}_{10} \mathrm{~N}_{2}\right)\left(\mathrm{Hg}_{2} \mathrm{Cl}_{5}\right)_{2} \cdot 3 \mathrm{H}_{2} \mathrm{O}$ using a solutionbased chemical method by hydrothermal methods has been synthesized and found to belong to the monoclinic system (space group $C 2 / c$ ). The optical properties and dielectric properties of Mercury (II) halides have been investigated and the optical constants have been evaluated. The UV-Vis

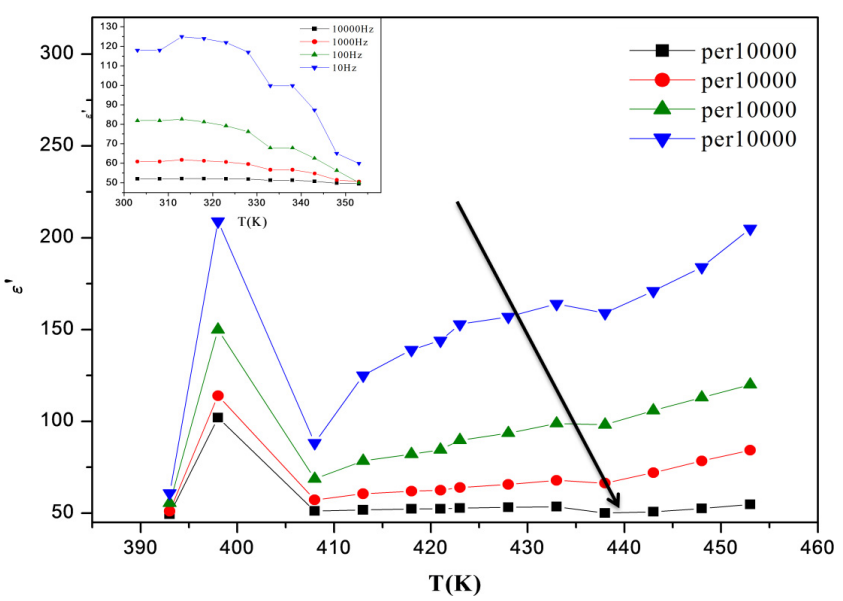

Fig. 21. Temperature dependence of the reel part $\varepsilon^{\prime}$ of complex permittivity at several frequencies.

spectroscopy was used to determine some of important parameters such as the band gap energy, the Urbach energy and the absorption coefficient. The optical band gap and Urbach energies of these samples were estimated from theoretical experiment. Additionally, the Tauc model was used to determine the optical gap energy. The absorption edge is determined by indirect transitions corresponding to an optical band gap of $(2.37 \mathrm{eV})$ for liquid and $(4.33 \mathrm{eV})$ for solid. The values of Urbach energy prove the presence of disorder in this hybrid compound. Finally, the observed change in dielectric properties is understood by considering the displacement damage introduced by temperatures in the decrease in the values of $\varepsilon, \varepsilon^{\prime \prime}$ and $t$ and. The imaginary $\left(\varepsilon^{\prime \prime}\right)$ part of the dielectric constant decreases as the frequency increases and it 
increases as the temperature increases. The presence of two relaxation peaks in the modulus loss spectra confirmed the grain and grain boundary contribution to the electrical response in the material. Nyquist plots show a non-Debye relaxation and the equivalent circuit is composed of a parallel combination of bulk resistance $R 1$, capacitance $C$, in series with a parallel combination of bulk boundary resistance $R 2$, capacitance $C 2$, and fractal capacity CPE.

\section{References}

${ }^{1}$ A. Morsali and M. Y. Masoomi, Structures and properties of mercury(II) coordination polymers, Coord. Chem. Rev. 253, 1882 (2009).

${ }^{2}$ M. S. Bharara, S. Parkin and D. A. Atwood, Solution and solidstate study of heteroleptic $\mathrm{Hg}$ (II)-thiolates: Crystal structures of $\left[\mathrm{Hg}_{4} \mathrm{I}_{4}\left(\mathrm{SCH}_{2} \mathrm{CH}_{2} \mathrm{NH}_{2}\right)_{4}\right]$ and $\left[\mathrm{Hg}_{4} \mathrm{I}_{8}\left(\mathrm{SCH}_{2} \mathrm{CH}_{2} \mathrm{NH}_{3}\right)_{2}\right] \mathrm{n} \cdot \mathrm{nH}_{2} \mathrm{O}$, Inorg. Chem. 45, 2112 (2006).

${ }^{3}$ C. Hu, I. Kalf and U. Englert, Pyridine complexes of mercury(ii) halides: Implications of a soft metal center for crystal engineering, Cryst. Eng. Comm. 9, 603 (2007).

${ }^{4}$ X.-F. Wang, Y. Lv, T. Okamura, H. Kawaguchi, G. Wu, W.-Y. Sun and N. Ueyama, Structure variation of mercury(II) halide complexes with different imidazole-containing ligands, Cryst. Growth Des. 7, 1125 (2007).

${ }^{5}$ G. Mahmoudi, A. Morsali and M. Zeller, Mercury(II) acetate/ thiocyanate coordination polymers with n-donor ligands, spectroscopic, thermal and structural studies, Inorg. Chim. Acta 362, 217 (2009).

${ }^{6}$ G. Mahmoudi and A. Morsali, Mercury(II) metal-organic coordination polymers with pyrazine derivatives, Cryst. Eng. Comm. 11, 1868 (2009).

7J. Yang, B. Wu, F. Zhuge, J. Liang, C. Jia, Y.-Y. Wang, N. Tang, X.-J. Yang and Q.-Z. Shi, Coordination networks from zerodimensional metallomacrocycle, one-dimensional chain to twodimensional sheet based on a ditopic diiminopyridine ligand and group 12 metals, Cryst. Growth Des. 10, 2331 (2010).

${ }^{8}$ A. B. Lago, E. S. Lang, B. Tirloni and E. M. Vazquez-Lopez, Synthesis and structural characterization of a binary metal cluster and a coordination polymer based on the mercury Bis(phenylselenolate) unit, Polyhedron 43, 170 (2012).

${ }^{9} \mathrm{~K}$. Huber, Wisconsin department of natural resources, A summary of cooperative water-resources investigations, Wisconsin Mercury Source Book, Vol. 56 (Bureau of Watershed Management, Madison, WI, 1997).

${ }^{10}$ M. F. Hawthorne and Z. Zheng, Recognition of electron-donating guests by carborane-supported multidentate macrocyclic lewis acid hosts: Mercuracarborand chemistry, Acc. Chem. Res. 30, 267 (1997).

${ }^{11}$ A. Tamayo, B. Pedras, C. Lodeiro, L. Escriche, J. Casabo, J. L. Capelo, B. Covelo, R. Kivekas and R. Sillanpaa, Inorg. Chem. 46, 7818 (2007); J. G. Melnick, K. Yurkerwich, D. Buccella, W. Sattler and G. Parkin, Exploring the Interaction of Mercury(II) by $\mathrm{N}_{2} \mathrm{~S}_{2}$ and $\mathrm{NS}_{3}$ anthracene-containing macrocyclic Ligands: Photophysical, Analytical, and Structural Studies, Inorg. Chem. 47, 6421 (2008).

${ }^{12}$ S. Park, S. Y. Lee and S. S. Lee, Inorg. Chem. 49, 1238 (2010); A. Caballero, R. Martinez, V. Lloveras, I. Ratera, J. Vidal-Gancedo,
K. Wurst, A. Tarraga, P. Molina and J. Veciana, Conformationally modulated intramolecular electron transfer process in a diaza[2,2] ferrocenophane, J. Am. Chem. Soc. 127, 15666 (2005).

${ }^{13}$ G. Mahmoudi, A. Morsali, L.-G. Zhu and Z. Anorg, Allg. Chem. 633, 539 (2007); G. Mahmoudi and A. Morsali, Cryst. Growth Des. 8, 391 (2008); G. Mahmoudi and A. Morsali, Mercury(II) iodide coordination polymers generated from polyimine ligands, Polyhedron 27, 1070 (2008).

${ }^{14}$ S. Chattopadhyay, K. Bhar, S. Das, S. Satapathi, H.-K. Fun, P. Mitra and B. K. Ghosh, Polyhedron 29, 1667 (2010); S. Satapathi, S. Chattopadhyay, S. Roy, K. Bhar, P. Mitra and B. K. Ghosh, J. Mol. Struct. 1030, 138 (2012); S. Satapathi, S. Choubey, S. Das, K. Bhar, P. Mitra, R. Ghosh and B. K. Ghosh, Synthesis, molecular and crystalline architectures, and properties of novel bis(bidentate) and bis(tridentate) Schiff base bridged dinuclear mercury(II)pseudohalides: Control of coordination numbers by varying denticities, J. Chem. Crystallogr. 42, 1060 (2012).

${ }^{15}$ R. Elwej, N. Hannachi, I. Chaabane, A. Oueslati and F. Hlel, Structural, characterization and AC conductivity of bis-2-amino-6picolinium tetrachloromercurate, $\left(\mathrm{C}_{6} \mathrm{H}_{9} \mathrm{~N}_{2}\right)_{2} \mathrm{HgCl}_{4}$, Inorg. Chemi. Acta 406, 10 (2013).

${ }^{16}$ Y. Baklouti and F. Zouari, Synthesis, Crystal structure, thermal and dielectric properties of a new semi-organic crystal: $2[\mathrm{~N}(2-$ aminoethyl)-1,3-propanediaminium] octachlorodimercurate, tetrachloromercurate, Clust. Sci. 26, 1215 (2015).

${ }^{17}$ R. Ben Hassen, A. Ben Salah and A. Daoud, DSC, X-Ray Diffraction and Raman studies in the two-dimensional compound $\mathrm{CH}_{3} \mathrm{NH}_{3} \mathrm{HgCl}(\mathrm{CN})_{2}$, Phys. Status Solidi. (B) 201, 371 (1997).

${ }^{18}$ R. Spengler, F. Zouari, A. Ben Salah and H. Burzlaff, Bis (4benzylpiperidinium) tetrachloromercurate, Acta Cryst C 53, 1566 (1997).

${ }^{19}$ L. Jin, S. W. Sun, D. H. Wu, D. H. Wu and Y. Zhang, Synthesis, structure and dielectric property of poly[(cyanomethyltriethylammonium) bis( $\mu 2$-chloro)-bis( $\mu 3$-chloro)-tri( $\mu 2$-bromo)trimercury(II)] and [cyanomethyltriethylammonium][bis $(\mu 2-$ chloro)-bis(dichloromercury(II))], Inorg. Chem. Comm. 35, 226 (2013).

${ }^{20}$ Y. Dang, X. Meng, K. Jiang, C. Zhong, X. Chen and J. Qin, A promising nonlinear optical material in the Mid-IR region: New results on synthesis, crystal structure and properties of noncentrosymmetric $\beta$ - $\mathrm{HgBrCl}$, Dalton Trans. 42, 9893 (2013).

${ }^{21}$ V. Crasta, V. Ravindrachary, R. F. Bhajantri and R. Gonsalves, Growth and characterization of an organic NLO crystal: 1-(4methylphenyl)-3-(4-methoxyphenyl)-2-propen-1-one, Cryst. Growth Des. 267, 129 (2004).

${ }^{22}$ S. Prabu, R. Nagalakshmi, J. Balaji and P. Srinivasan, Synthesis, crystal growth, studies on vibrational spectroscopy and nonlinear optical properties of 4-methoxy-4'-chlorochalcone, Mater. Res. Bull. 50, 446 (2014).

${ }^{23}$ M. Amalanathan, I. Hubert Joe and V. K. Rastogi, Molecular structure and vibrational spectral investigation of charge transfer NLO crystal naphthalene picrate for $\mathrm{THz}$ application, Spectroc. Acta A 108, 256 (2013).

${ }^{24}$ Y. Baklouti, N. Chaari, H. Feki, N. Chniba-Boudjada and F. Zouari, Crystal structure, vibrational studies, optical properties and DFT calculations of 2-amino-5-diethyl-aminopentanium tetrachlorocadmate (II), Spectrochim. Acta A 136, 397 (2015).

${ }^{25}$ A. Kessentini, M. Belhouchet, J. J. Suñol, Y. Abid and T. Mhiri, Synthesis, structural, photoluminescence, vibrational and DFT 
investigation of the bis (4-aminopyridinium) tetrachloridocuprate(II) monohydrate, J. Lumin. 149, 341 (2014).

${ }^{26}$ G. Meyer and P. Nockemann, Reactivity of ammonium chloride/ mercuric chloride mixtures with monel containers. The new compounds $\left(\mathrm{NH}_{4}\right)_{2}\left(\mathrm{NH}_{3}\right) \times\left[\mathrm{Ni}\left(\mathrm{NH}_{3}\right)_{2} \mathrm{Cl}_{4}\right]$ and $\left(\mathrm{NH}_{4}\right)_{5} \mathrm{Cl}_{2}\left[\mathrm{CuCl}_{2}\right]$ $\left[\mathrm{CuCl}_{4}\right]$, J. Solid-State Chem. 162, 254 (2001).

${ }^{27}$ P. G. Lacroix, Organic nonlinear optical chromophores in an inorganic environment. Toward an interplay between magnetism, conductivity, and nonlinear optics, Chem. Mater. 13, 3495 (2001).

${ }^{28}$ H. O. Desseyn, B. Slootmaekers, The vibrational spectra and force constants of the planar $\mathrm{CuCl}_{42}$ - ion in bis(2-aminobenzothiazolium)tetrachlorocuprate(II), Inorg. Chim. Acta 56, 113 (1989).

${ }^{29}$ M. M. Zhao and P. P. Shi, Bis(4-fluoroanilinium) tetrachloridocuprate(II), Acta Cryst. 66, 656 (2010).

${ }^{30}$ A. Jellibi, I. Chaabane and K. Guidara, Spectroscopic ellipsometry and UV-vis studies at room temperature of the novel organicinorganic hybrid of salt Bis (4-acetylanilinium) tetrachlorocadmiate, Phys. E:Low-Dimens. Syst. Nanostruct. 79, 167 (2016).

${ }^{31}$ M. AmineFersi, I. Chaabane, M. Gargouri and A. Bulou, Raman scattering study of temperature induced phase transition in $\left[\mathrm{C}_{8} \mathrm{H}_{10} \mathrm{NO}\right]_{2}\left[\mathrm{ZnCl}_{4}\right]$, AIP Adv. 5, 087127 (2015).

${ }^{32}$ A. Jarboui, B. Louati, F. Hlel and K. Guidara, Synthesis, 13C NMR-MAS, AC conductivity and structural characterization of $\left[\mathrm{C}_{7} \mathrm{H}_{12} \mathrm{~N}_{2}\right] \mathrm{ZnCl}_{4}$, Alloys Compd. 503, 340 (2010).

${ }^{33}$ S. Sinha, S. K. Chatterjee, J. Ghosh and A. K. Meikap, Electrical transport properties of consolidated $\mathrm{ZnSe}$ quantum dots at and above room temperature, Curr. Appl. Phys. 15, 555 (2015).

${ }^{34}$ H. B. Duan, S. S. Yu and H. Zhou, Alternating-current conductivity and dielectric relaxation of bulk iodoargentate, Mater. Res. Bull. 65, 137 (2015).

${ }^{35}$ I. B. Saad, N. Hannachi, T. Roisnel and F. Hlel, Ionic organicinorganic $\left(\mathrm{C}_{6} \mathrm{H}_{10} \mathrm{~N}_{2}\right) \quad\left(\mathrm{Hg}_{2} \mathrm{Cl}_{5}\right)_{2} \cdot 3 \mathrm{H}_{2} \mathrm{O}$ compound: Structural study, hirshfeld surface, thermal behavior and spectroscopic studies, J. Mol. Struct. 1178, 201 (2019).

${ }^{36}$ G. R. Kumar. J. Vivekanandan. A. Mahudeswaran and P. S. Vijayanand, Synthesis and characterization of novel poly(anilineco-m-aminoacetophenone) copolymer nanocomposites using dodecylbenzene sulfonic acid as a soft template, Iran Polym. J. 22, 923 (2013).

${ }^{37}$ A. Abkari, I. Chaabane and K. Guidara, Synthesis, crystal structure, spectroscopic characterization and optical properties of bis(4acetylanilinium) tetrachlorocobalt (II), Phys. E: Low-dimensional Syst. Nanostruct. 86, 210 (2017).

${ }^{38}$ Y. Baklouti, N. Chaari, H. Feki, N. Chniba-Boudjada and F. Zouari, Crystal structure, vibrational studies, optical properties and DFT calculations of 2-amino-5-diethyl-aminopentanium tetrachlorocadmate (II), Mol. Biomol. Spectros. 136, 397 (2015).

${ }^{39}$ A. Kessentini, M. Belhouchet, J. J. Suñol, Y. Abid and T. Mhiri, Synthesis, crystal structure, vibrational spectra, optical properties and theoretical investigation of bis (2-aminobenzimidazolium) tetraiodocadmate, J. Mol. Struct. 1039, 207 (2013).

${ }^{40}$ A. Jellibi, I. Chaabane and K. Guidara, Spectroscopic ellipsometry and UV-vis studies at room temperature of the novel organic-inorganic hybrid of salt Bis (4-acetylanilinium) tetrachlorocadmiate, Phys. E: Low-dimensional Syst. Nanostruct. 79, 167 (2016).

${ }^{41}$ A. Eshaghi and A. Graeli, Optical and electrical properties of indium tin oxide (ITO) nanostructured thin films deposited on polycarbonate substrates "thickness effect", Optik Int. J. Light Electron. Opt. 125, 1478 (2014).
${ }^{42}$ A. Ayeshamariam, S. Ramalingam, M. Bououdina and M. Jayachandran, Preparation and characterizations of $\mathrm{SnO}_{2}$ nanopowder and spectroscopic (FT-IR, FT-Raman, UV-Visible and NMR) analysis using HF and DFT calculations, Spectroc. Acta A 118, 1135 (2014).

${ }^{43}$ A. Bougrine, A. El Hichou, M. Addou, J. Ebothé, A. Kachouna and M. Troyon, Structural, optical and cathodoluminescence characteristics of undoped and tin-doped $\mathrm{ZnO}$ thin films prepared by spray pyrolysis, Mater. Chem. Phys. 80, 438 (2003).

${ }^{44}$ M. S. Shakeri and M. Rezvani, Optical band gap and spectroscopic study of lithium alumino silicate glass containing Y3+ ions, Spectroc. Acta A 79, 1920 (2011).

${ }^{45}$ R. Lefi, F. B. Naser and H. Guermazi, Structural, optical properties and characterization of $\left(\mathrm{C}_{2} \mathrm{H}_{5} \mathrm{NH}_{3}\right)_{2} \mathrm{CdCl}_{4},\left(\mathrm{C}_{2} \mathrm{H}_{5} \mathrm{NH}_{3}\right)_{2} \mathrm{CuCl}_{4}$ and $\left(\mathrm{C}_{2} \mathrm{H}_{5} \mathrm{NH}_{3}\right)_{2} \mathrm{Cd}_{0.5} \mathrm{Cu}_{0.5} \mathrm{Cl}_{4}$ compounds, J. Alloy. Compound. 696, 1244 (2017).

${ }^{46}$ S. Kumar, P. K. Singh and G. S. Chilana, Study of silicon solar cell at different intensities of illumination and wavelengths using impedance spectroscopy, Sol. Energy Mater. Sol. Cells 93, 1881 (2009).

${ }^{47}$ K. Karoui, A. Ben Rhaiem, F. Hlel, M. Arous and K. Guidara, Dielectric and electric studies of the $\left[\mathrm{N}\left(\mathrm{CH}_{3}\right)_{4}\right]\left[\mathrm{N}\left(\mathrm{C}_{2} \mathrm{H}_{5}\right)_{4}\right] \mathrm{ZnCl}_{4}$ compound at low temperature, Mater. Chem. Phys. 133, 1 (2012).

${ }^{48}$ S. Nasri, M. Megdiche, K. Guidara and M. Gargouri, Study of complex impedance spectroscopic properties of the $\mathrm{KFeP}_{2} \mathrm{O}_{7}$ compound, Ionics 19, 1921 (2013).

${ }^{49}$ H. Mahamoud, B. Louati, F. Hlel and K. Guidara, Impedance spectroscopy study of $\mathrm{Pb}_{2} \mathrm{P}_{2} \mathrm{O}_{7}$ compound, Ionics 17, 223 (2011).

${ }^{50} \mathrm{~S}$. Brahma et al., AC impedance analysis of $\mathrm{LaLiMo}_{2} \mathrm{O}_{8}$ electroceramics, Physica B 355, 188 (2005).

${ }^{51}$ D. C. Sinclair and A. R. West, Impedance and modulus spectroscopy of semiconducting $\mathrm{BaTiO}_{3}$ showing positive temperature coefficient of resistance, J. Appl. Phys. 66, 3850 (1989).

${ }^{52}$ I. M. Hodge, M. D. Ingram and Q. A. R. West, Impedance and modulus spectroscopy of polycrystalline solid electrolytes, J. Electroanal. Chem. Interfacial Electrochem. 74, 125 (1976).

${ }^{53}$ P. B. Macedo, C. T. Moynihan and R. Bose, Study of structural and electrical properties of a new type of complex tungsten bronze electroceramics; $\mathrm{Li}_{2} \mathrm{~Pb}_{2} \mathrm{Y}_{2} \mathrm{~W}_{2} \mathrm{Ti}_{4} \mathrm{~V}_{4} \mathrm{O}_{30}$, Phys. Chem. Glas. 13, 171 (1972).

${ }^{54} \mathrm{G}$. Williams and D. C. Watts, Non-symmetrical dielectric relaxation behaviour arising from a simple empirical decay function, Trans. Faraday Soc. 66, 80 (1970).

${ }^{55}$ R. Ayouchi, D. Leien, F. Martin, M. Gabas, E. Dalchiele and J. R. Ramos-Barrodo, Preparation and characterization of transparent $\mathrm{ZnO}$ thin films obtained by spray pyrolysis, Thin Solid Films $\mathbf{6 8}$, 426 (2003).

${ }^{56}$ A. N. Papathanassiou, Novel feature of the universal power law dispersion of the ac conductivity in disordered matter, J. NonCryst Solids 352, 5444 (2006).

${ }^{57}$ F. Alvarez, A. Alegria and J. Colmenero, Interconnection between frequency-domain Havriliak-Negami and time-domain Kohlrausch-Williams-Watts relaxation functions, J. Phys. Rev. B 47, 125 (1993).

${ }^{58}$ R. D. Gould, A. K. Hassan et al., A.C. electrical properties of thermally evaporated thin films of copper phthalocyanine, Thin Solid Films 223, 334 (1993).

${ }^{59}$ J. Suchanicz, The low-frequency dielectric relaxation $\mathrm{Na}_{0.5} \mathrm{Bi}_{0.5-}$ $\mathrm{TiO}_{3}$ ceramics, J. Mater. Sci. Eng B 55, 114 (1998). 
${ }^{60}$ J. E. Bauerle, Study of solid electrolyte polarization by a complex admittance method, J. Phys. Chem. Solids 30, 2657 (1969).

${ }^{61} \mathrm{G}$. Williams and D. C. Watts, Non-symmetrical dielectric relaxation behaviour arising from a simple empirical decay function,

Trans. Faraday Soc. 66, 80 (1970).
${ }^{62}$ A. Oueslati, F. Hlel, K. Guidara and M. J. Gargouri, AC conductivity analysis and dielectric relaxation behavior of $\left[\mathrm{N}\left(\mathrm{C}_{3} \mathrm{H}_{7}\right)_{4}\right]_{2} \mathrm{Cu}_{2} \mathrm{Cl}_{6}$, Alloys Compd. 492, 508 (2010). 